Article

\title{
Research on the Colors of Military Symbols in Digital Situation Maps Based on Event-Related Potential Technology
}

\author{
Yafeng Niu ${ }^{1, *}$, Guorui Ma ${ }^{1}$, Wei Xue ${ }^{1}$, Chengqi Xue ${ }^{1}$, Tianyu Zhou ${ }^{1}$, Yue Gao ${ }^{1}$, Hongrui Zuo ${ }^{1}$ \\ and Tao Jin ${ }^{2}$ \\ 1 School of Mechanical Engineering, Southeast University, Nanjing 211189, China; \\ 220184322@seu.edu.cn (G.M.); 220163574@seu.edu.cn (W.X.); ipd_xcq@seu.edu.cn (C.X.); \\ 220184329@seu.edu.cn (T.Z.); 220184304@seu.edu.cn (Y.G.); 220190379@seu.edu.cn (H.Z.) \\ 2 Mechanical and Electrical Engineering Institute, China University of Petroleum, Qingdao 266580, China; \\ jzht126@163.com \\ * Correspondence: nyf@seu.edu.cn; Tel.: +86-13505149958
}

Received: 17 May 2020; Accepted: 25 June 2020; Published: 30 June 2020

check for updates

\begin{abstract}
Under the trend of increasingly informationalized military operations and the increasing maneuverability of combat units, military commanders have put forward higher requirements for the accuracy and promptness of information on battlefield situation maps. Based on the sea battlefield, this paper studies the pros and cons of the color matching of military symbols on sea situation maps. Fifteen colors, where each Hue had five colors, were chosen using the Munsell Color System according to Chroma axis and the Value axis on a span of 2 and 4. By collecting and analyzing the P300 EEG data, reaction time data, and accuracy data of 20 subjects, a better color matching selection of military symbols on pure color $(L=85, a=-10$, and $b=-23$ ) sea situation maps is put forward, and the conclusions are as follows: (1) the different colors all cause the P300 component in EEG experiment. Among them, the P300 amplitude that is caused by military symbols with lower Chroma is smaller and the latency is shorter, indicating that the user experience and efficiency of low Chroma color symbols will be better than those with high Chroma color symbols. (2) High Value color map military symbols cause higher P300 amplitude and longer latency. According to the results above, this paper puts forward three optimized colors, namely, blue $(L=39, a=20$, and $b=-49)$, green $(L=80, a=-72$, and $b=72)$, and red $(L=20, a=41$, and $b=28)$. Additionally, three map interfaces were designed to confirm the validity of these colors. By means of applying the NASA-TLX (Task Load Index) scale to evaluate the task load of the confirmation interfaces, it can be concluded that these three optimized colors are preferred by users who are skilled in GIS and interface design. Therefore, the research conclusion of this paper can provide important reference values for military map design, which is helpful in shortening the identification and judgment time during the use of situation maps and it can improve users' operation performance.
\end{abstract}

Keywords: situation map; color; P300; GIS; symbol design; ERP

\section{Introduction}

Nowadays, traditional human-computer interfaces have been replaced by digital human-computer interfaces in most industrial control rooms. Operators place greater emphasis on the rationality of cognitive processes and the reliability of using such processes [1]. The main elements of a digital interface can be divided into five parts-icon, space, color, layout, and interaction - of which color is a particularly important factor affecting the digital interface. 
In the field of color coding, Ahlstrom and Arend explored the influence of color matching on the work performance of the operation interface in the air traffic control (ATC) system, and concluded that increasing the significance of Value contrast in color coding can enhance the display level of information [2]. The research results of Chiang et al. showed that, if map blocks are not distinguished by color coding in a GIS system -in other words, if map images cannot be properly preprocessed-most map interface display results will fail to meet users' expectations [3]. Li et al. also proposed a method of adjusting the Value and enhancing the color coding to reduce the problem of reduced visibility that is caused by complex visual graphics [4].

In the field of interface color ergonomics, Boulhic studied the monitoring interface of a ship in the engine room and compared the effects of two-color codes on the performance of novices and experts in object search tasks. The results showed that the two-color version of the specific standard increased the mental load and search time of novices, while expert users had more difficulty in identifying the liquid symbols that are represented by the two-color codes than novices [5]. Regarding human observation, Yang applied the color BCDS (Business Color Design System) in order to study the psychological effects of the application of color in the flat style interface, which improved the comfortableness of human-computer interactions [6]. Sun et al. proposed an image-based interface color matching method that is based on the subjective memory and experience of the human brain [7].

Based on user requirements for map interfaces, some scholars have applied design methods in the GIS map interface to improve the efficiency during use. Tian et al. designed a data model of the integrated storage of geographic information data and cartographic data, driving the adaptive design of maps. It was proven that the method of automatic adjustment of GIS map element location and layout not only improved users' efficiency, but also reduced the physiological and psychological burdens [8]. In addition, Scholz proposed that over-boundary ambiguity and color Value, as well as shade, are the best visual presentation forms for bivariate maps to represent uncertainty [9]. In a study of land usage classification, Akcay et al. analyzed the segmentation forms of different shapes, colors, and densities, which improved the display accuracy of their classification results [10]. Shive et al. used a visual search model to select colors for the icons displayed on maps, which indicated the best selection of colors for icons on a GIS map and offered predictions of the visual search model in order to minimize the time that it takes to search icons. The experimental results showed that the visual search experimental model can provide a reference for icon colors, so as to minimize the search time for icons in a GIS system [11]. In a study of map presentation form, Skopeliti proposed an optimized design scheme by studying the projection, direction, scale, symbols, and other elements of online maps [12].

In the process of map information research, the main experimental methods that were adopted by researchers are the subjective evaluation method and the objective measurement method. Based on the relevant theories of linguistics, Li et al. analyzed the key components of personalized map symbols, such as situational semantics and symbol statement grammar, and proposed design strategies for personalized map symbols [13]. Tian proposed a semantically driven hierarchical map symbol design method in the study of map symbols, and fully explored the values of the conceptual semantic components of map symbols in the field of symbol design. Furthermore, the scholar carried out design improvements and cognitive experiments. The results showed that the cognition efficiency of improved symbols is better and the information transmission rate is relatively stable [14].

$\mathrm{Li}$, Tian, and other researchers mainly used subjective evaluation methods to study GIS interfaces and colors, while there are few cases of objective experiments based on physiological data. Ooms innovatively applied eye tracking technology to the fields of cartography and GIS. By analyzing eye movement indicators, such as fixation times and the duration that users' eyes focus on an element of the map, users' search strategies of dynamic and interactive maps were revealed [15]. Additionally, Coltekin evaluated two legend designs of soil landscape maps by means of analyzing the eye movement index of users reading the map, and finally put forward suggestions on the design of such maps [16]. Liu and Chen explored the influence of border design of dot map symbols on users' cognitive maps 
through eye movement experiments, when comparing the different cognitive effects of three schemes, and further proposed the border design scheme of dot map symbols on network tourism maps [17].

Additionally, in the study of user cognitive processes, objective physiological experiments also include electroencephalogram (EEG) technology, which includes event-related potential (ERP), functional magnetic resonance imaging (FMRI), functional near infrared imaging (fNIRS), and other such technology. These effective and real-time neuroimaging methods can measure brain activity in the process of early cognitive change, so as to understand the inner cognitive mechanism of users while using digital interfaces. Babiloni et al. achieved more accurate temporal and spatial resolution of EEG technology through continuous improvements of EEG technology [18]. FMRI plays an important role in cognitive science because of its high spatial resolution. Rahm et al. used FMRI technology to study the relationship between working memory load and frontal parietal lobe activation, providing a reference mechanism for the study of decision making-related working memory [19]. ERP is a kind of evoked EEG, which refers to the specific potential that is generated in the brain when a user receives a specific stimulus. It has a high temporal resolution, which can reveal the characteristics of material processing in the early cognitive process. ERP is often used to measure the load of a specific task. Perri used ERP-related technologies to conduct his research when he explored the relationship between visual load and the visual area of the brain [20].

Among ERP components, P300 is a positive wave in the EEG components, which usually occurs $300 \mathrm{~ms}$ after a specific stimulus and the amplitude of P300 is widely used in assessing the task loads. The amplitude of P300 is relatively high, usually $5-20 \mu \mathrm{V}$, and sometimes up to $40 \mu \mathrm{V}$. The amplitude of P300 is believed to be related to the difficulty of the task [21-24]. Chen et al. chose amplitude, latency, and other components of P300 as the task feature selection criteria [25]. Zhang evaluated and measured the psychological load of pilots before and after stress by comparing the changes of P300 amplitude and latency [26]. Jin et al. conducted an EEG experiment on situational awareness of the fighter digital graphical interface [27]. Moreover, Yeh et al. introduced the ERP method into the study of the color of interfaces, exploring, in-depth, the state of color in the early cognitive process [28].

It can be concluded from the above-mentioned research that EEG technology has been widely applied in a variety of scientific fields and it has obtained accurate and practical research results by virtue of its characteristics of accurate recording, stable data, millisecond resolution of time, event synchronization, and strong neuro-endogenous function.

Throughout most of the GIS map interface design and research methods in the field of cognitive science, there are still few studies that have applied objective EEG measurement methods. EEG experimental methods have higher precision and reliability than other methods, and can they be adapted for GIS and interface-relevant cross research. Hence, EEG technology was chosen in this paper in order to evaluate the color of military symbols in the interface of situation maps.

\section{Related Work}

\subsection{Situation Maps}

A situation map usually consists of a digital map base, situational elements, and annotated information. Situational elements mainly include map symbols, queue numbers, bullet points, etc. [29]. Figure 1 shows the FBCB2 system used by the U.S. Army, which contains the common elements of a situation map, and where the blue and red map markers in the figure are military symbols.

For the interface of situation maps, GIS management and the display of military symbols are two basic functions. The main functions of GIS management are map loading, layer management, map operation, map query, and measurement. The type of maps that are loaded by the system are variable, and include, for instance, planar graphs, image maps, joint combat graphs, and utility maps [30]. This paper adopted a map from "Military Map" for research, as shown in Figure 2. "Military Map" is a web application that is designed for visualizing and planning military exercises and missions. This program can both search and add military symbols provided by MIL-STD-2525C. 

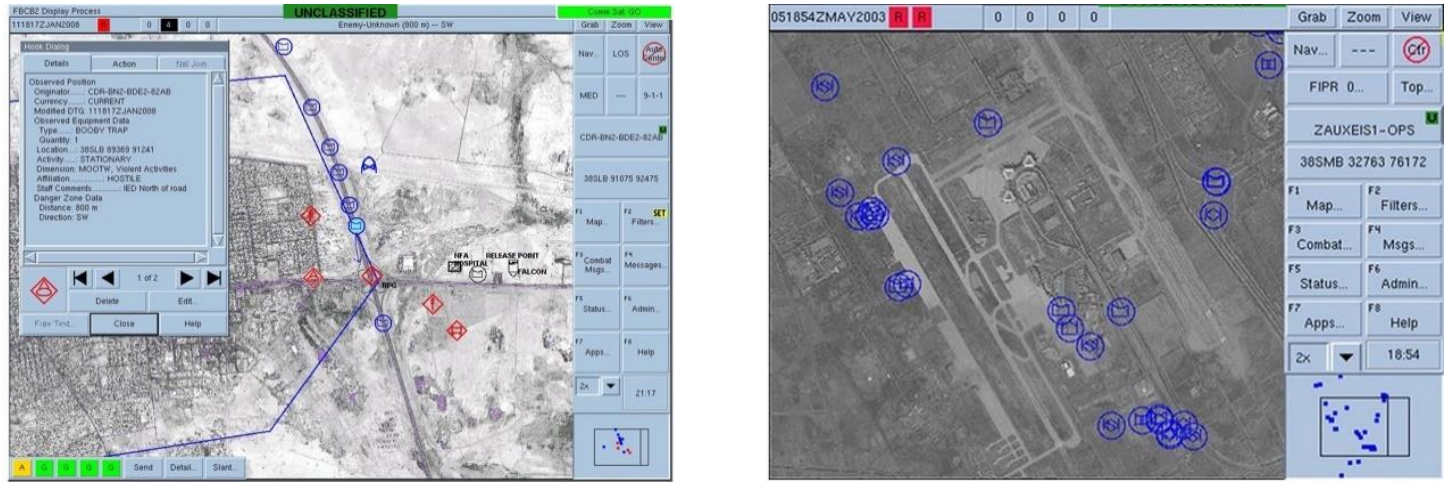

Figure 1. The FBCB2 situation map interface.

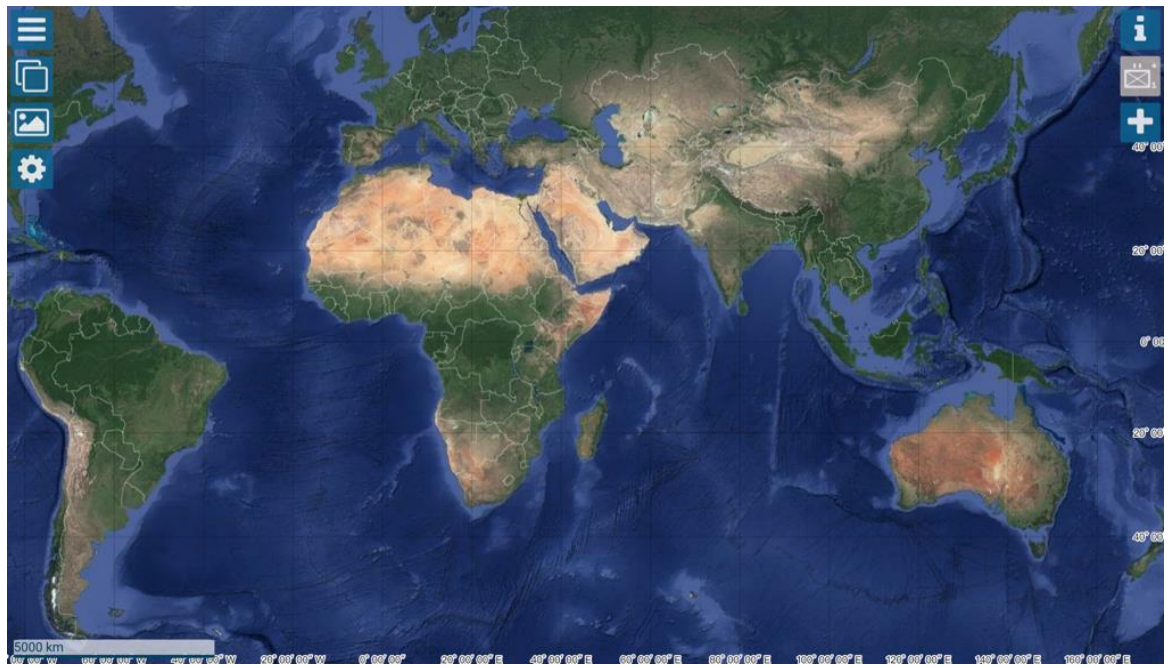

Figure 2. The "Military Map" interface.

There are five main types in the "Military Map" application: hybrid, roadmap, roads, satellite, and terrain (Figure 3). Among them, the terrain map model is commonly used in situation maps.

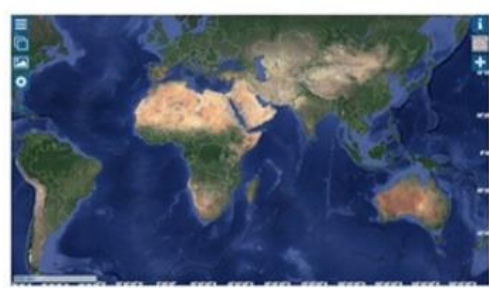

Hybrid

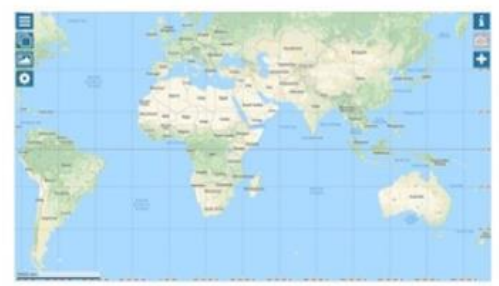

Roadmap

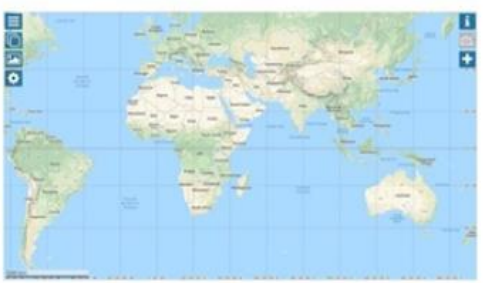

Terrain

Figure 3. The five types of maps in "Military Map" (The first line: Hybrid, Roadmap; The second line: Road, Satellite, Terrain). 
The "Military Map" terrain mode (Figure 4) shows a typical map pattern. Among the different elements in terrain maps, the ocean is an important living environment for human beings. In today's world, the ocean reflects more realistic and strategic significance [31]. Therefore, a "high seas" map of pure color was used as the interface background of the experiments in this paper, which is conducive to the acquisition of lower noise data in the objective physiological experiments.
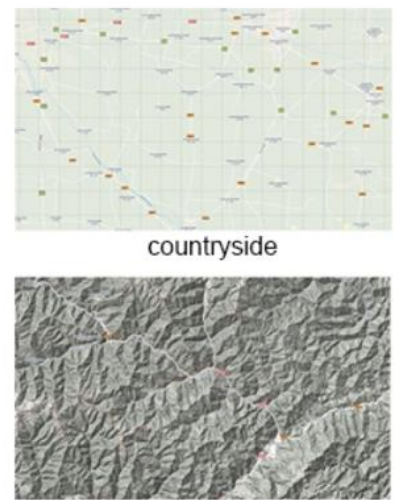

mountain (high altitude)

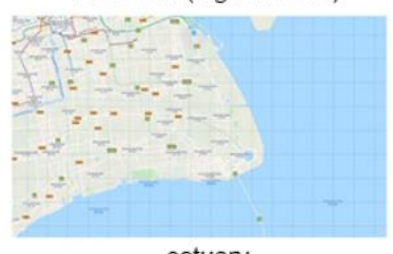

estuary

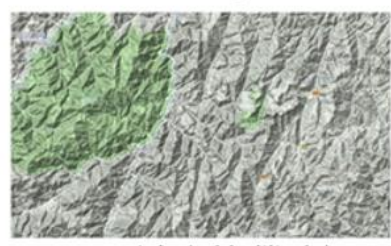

mountain (mid altitude)

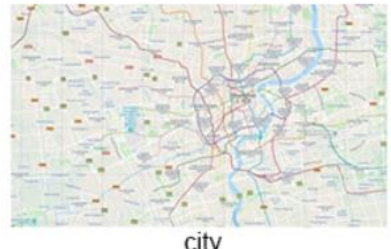

city

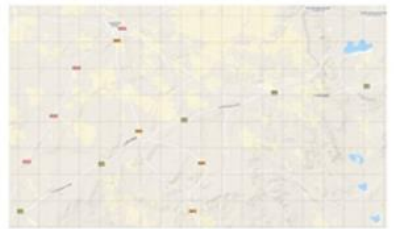

plateau

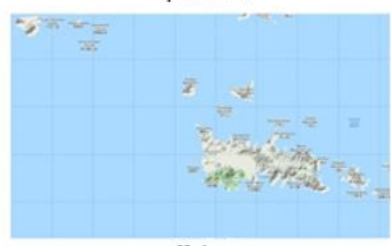

offshore

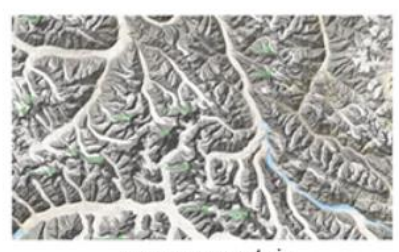

snow mountain

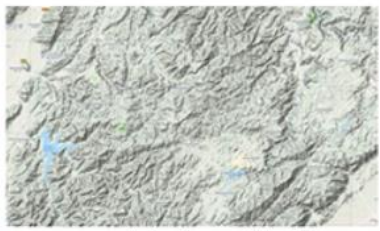

mountain (low altitude)

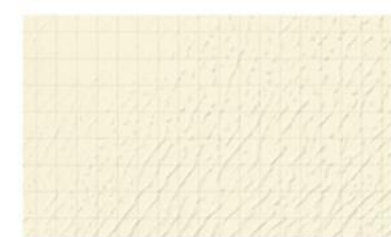

desert

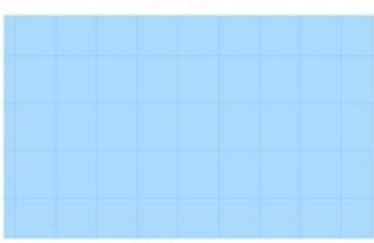

high seas

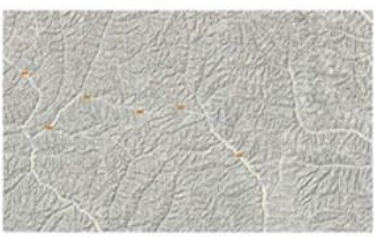

rough plateau

Figure 4. Twelve types of terrain map (The first line: countryside, city, mountain (low altitude); The second line: mountain (high altitude), plateau, desert; The third line: estuary, offshore, high seas; The fourth line: mountain (mid altitude), snow mountain, rough plateau).

In addition to the background map in the interface, another component of the interface of situation maps is that of the map symbols that refer to the military symbols, especially in this paper. The main components of military symbols are described in MIL-STD-2525C [32]. The elements of a military symbol consist of the frame, the padding, and the alphabetic mark, as shown in Figure 5.

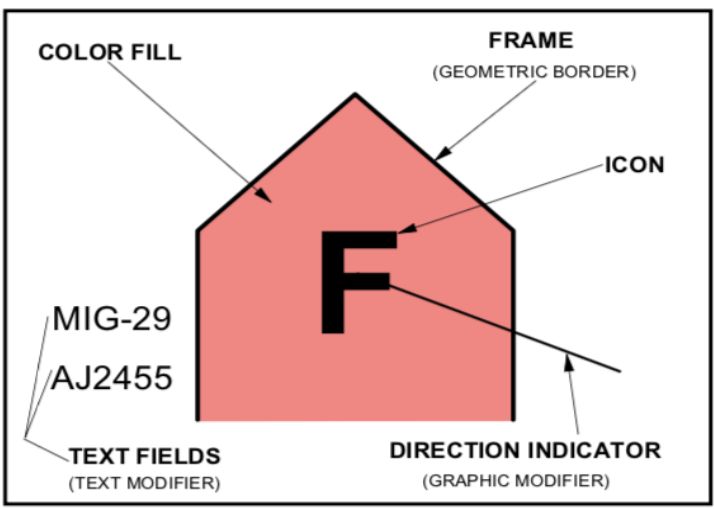

Figure 5. Components of a military tactical symbol [32]. 
Military symbols can be shown with different display options such as planar mode, linear mode, and point mode [32], as shown in Figure 6.

\begin{tabular}{|l|l|}
\hline Examples & \multicolumn{1}{c|}{ Description } \\
\hline & $\begin{array}{l}\text { Frame: ON (black or white depending on background) } \\
\text { Fill: ON (use default color indicating standard identity) } \\
\text { Icon: ON (black or white) }\end{array}$ \\
\hline & $\begin{array}{l}\text { Frame: ON (use default color indicating standard identity) } \\
\text { Fill: OFF } \\
\text { Icon: ON (use default color indicating standard identity) }\end{array}$ \\
\hline & $\begin{array}{l}\text { Frame: OFF (none) } \\
\text { Fill: ON (use default color indicating standard identity) } \\
\text { Icon: OFF (none) }\end{array}$ \\
\hline
\end{tabular}

Figure 6. Military symbol display options [32].

Among the three display options of military symbols, linear display pattern without frames are the most susceptible to the color and background of an interface. Therefore, the linear display manner in MIL-STD-2525C were selected for the experiment.

\subsection{Color Heories}

There are many ways for people to perceive external information. Relevant experiments show that $80 \%$ of the information that people can perceive is obtained by vision. In visual perception, color accounts for a very large factor. In the first $20 \mathrm{~s}$ when a person observes an object, color sensation accounts for $80 \%$ of the perceived information, and morphological sensation for $20 \%$ [33]. Different colors give people different perception depths, resulting in visual perception layers, which is of great significance for the design of an interface with multiple layers that overlap to display information, such as a map interface.

The Munsell Color System (MCS) is one of the most commonly used color systems in the world. MCS arranges different colors into particular cards with a unique number in an orderly manner based on H (Hue), V (Value), and C (Chroma), as shown in Figure 7a. The advantage of MCS system is the same step between two colors and the characteristic of equidistant in visual perception [34].
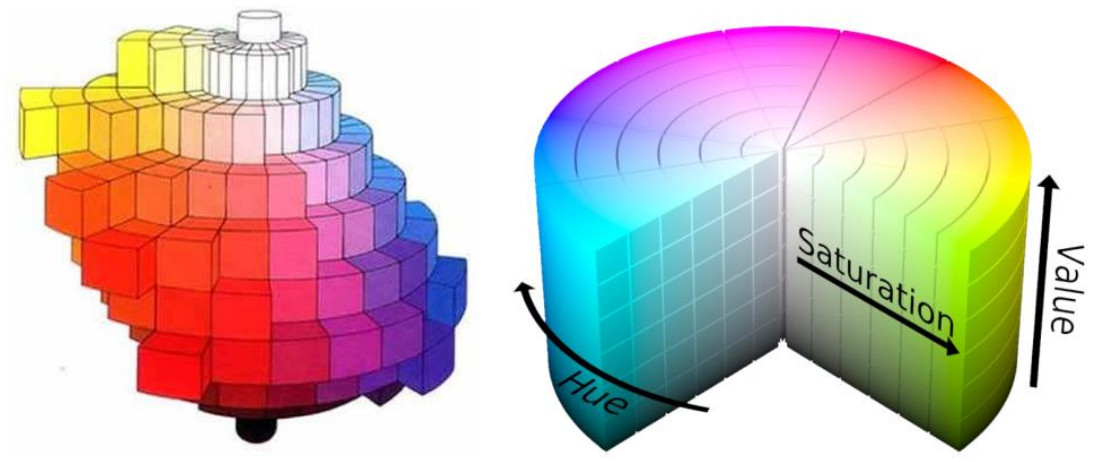

(a). The Munsell Color System (b). HSV (HSB) Color System.

Figure 7. Different Color Systems (Source: (a). www.haiwa.me/index.php/2017/03/16/color-patternlearning/ (b). https://www.zcool.com.cn/article/ZMTEzMDk3Ng==.html). 
However, there are more than a billion colors in the computer. MCS colors cannot represent all colors in the digital display equipment, and the separation of colors on CIE1976 chromaticity diagram is not even. HSV (HSB) color system is mostly used in digital design software for its user-centered using habits, which addresses the problems of MCS and provides a more user-friendly method for selecting colors according to $\mathrm{H}$ (Hue), $\mathrm{S}$ (Saturation), and V (Value), which is the same meaning of B (Brightness) in somewhere else. Therefore, the concept of HSV color system combined with the MCS color arrangement is used in this article because of the similarity of MCS and its convenience in practical application.

In digital interfaces, the color relationship between the target and the background allow users to obtain a visual sense of distance. The correct selection of colors and the reasonable adjustment of the relationship between the target and background are very important for evaluation and testing [35].

At the same time, metamerism is an affecting element in color-based study. The origin colors of an object could be different under the influence of luminance, sensors, lighting devices, and so on, according to Prasad and Wenhe [36]. It reminds that the lighting system and display devices should keep consistent according to the same indexes of color temperature and color space in the experiment.

Additionally, the different standard observer angles, such as two-degree or 10-degree, could cause some differences. Ikeda et al. had discussed the differences between two-degree and 10-degree standard observer angle [37]. Regarding to this problem, Trezona found that the 10-degree standard observer angle had more applying value than two-degree in practical application, such as photography, business, printing, and interface, because 10-degree visual angles were more common in the real daily scenarios [38].

\subsection{EEG Technology}

EEG was first discovered in 1875 and, in 1964, Grey Walter et al. outlined the components of cognitive ERP, marking the beginning of a new era of ERP research [39]. The components of ERP observed in recent years include, but are not limited to, mismatched negative wave (MMN), motion-related potential, N400, P300, recognition potential (RP), and vision C1/P1/N2.

In a study of MMN, Clifford et al. proposed a visual mismatching negative wave (vMMN) when investigating the changes of brain in the process of color perception, providing possible evidence for the classification and coding of color pre-attention [40]. Oxner et al. proposed that changes in the layout of an interface would cause changes in MMN, P2-N2, and P300 [41]. However, MMN is mainly caused by hearing, and the classical MMN differential wave can be obtained in the classical Oddball paradigm. Wiens $\mathrm{S}$. et al. proposed that there was no correlation between working memory capacity and visual load and MMN [42]. Based on this, Male et al. wanted to prove the real vMMN through experiments, and finally came to the conclusion that the real vMMN was an unstable phenomenon, which is also dependent on the experimental parameters that are to be determined [43].

$\mathrm{N} 400$ is a component that is related to language processing, in particular, the extraction of semantic information from long-term memory. However, with the deepening of research, it has been shown that $\mathrm{N} 400$ is not only related to semantic processing, but can still be induced when faces, pictures, and other nonverbal stimuli appear [44]. Liu et al. studied and obtained the cumulative priming effect of early visual information on target sound through the analysis of N400 components [45]. Rama et al. studied the language system of infants and found that the priming effect of N400 was significant in 2-year-olds, which was similar to that of infants with richer vocabulary at 18 months [46]. Proverbio used N400 to study the visual information processing of human gestures, and concluded that visual information and language input have similar processing patterns [47].

In the research works of P300, Niu et al. verified, through experiments, that the latency and amplitude of P300 increase as the difficulty of the task increases, indicating that the amplitude of P300 is related to the level of working memory [22]. From the perspective of linguistics, Morrison and Taler verified that there was also a correlation between the amplitude of the P300 component and the language processing load: the larger the load, the higher the amplitude of P300 [48]. Ting Han et al. 
also found a similar relationship in their research related to memory [49]. When exploring interfacial visual motor stimulation, Berti et al. used the P300 component for analysis, and concluded that parietal lobe and occipital lobe electrodes were highly correlated with visual stimulation [50]. Liu et al. also found a difference in color judgment between the left and right visual fields when using P300 [51]. In addition, Fermin M et al. also used the P300 component to explore the influence of color on different words in the early cognitive process [52].

When considering the above-mentioned different effects of the different EEG components in various types of studies, it is evident that $\mathrm{P} 300$ plays an important role in the study of color stimulation and cognitive performance. Therefore, the P300 component was selected for the evaluation and analysis of the experimental indicators in this paper.

\section{Methodology}

\subsection{Equipment and Subjects}

This paper aimed to explore the relationship between the different colors of military symbols on maps and the influence of visual search through ERP and behavior experiments. By analyzing the ERP P300 component's amplitude and latency, combining the behavioral data of accuracy and reaction time, an optimal color scheme for military symbols on situation maps is put forward.

The hardware of the experimental equipment used in this experiment is that of the EEGO MyLab EEG system produced by ANT company with 32 channels. The stimuli were placed on a screen that was 21.5 inches in physical size and it had a resolution of $1920 \times 1080$ pixels.

The software used in experiments were E-Prime 2.0, ASA, and SPSS. E-Prime 2.0 was used to present the stimuli and collect the behavioral data from experiments. Meanwhile, ASA was used to collect and analyze the EEG data, and SPSS was used to analyze the behavioral data collected.

The subjects of this experiment were students of the Southeast University, including 10 males and 10 females [53]. All of the subjects are skilled in geo-information and familiar with map interface design, ensuring the effectiveness and representativeness of the experiment. The age of all the subjects ranged from 22 to 27 , with an average age of 24.75, and the standard deviation of subjects' age was 1.089. None of the 20 subjects were color blind or weak, and all were right-handed. None of the subjects had a history of mental illness or brain trauma.

\subsection{Experiment Materials}

For collecting low-noise EEG waves, the experiment task in EEG experiment should be designed as not too difficult and recognizing symbols directions is the main task. Therefore, symbols in the experiment task should have directions. However, the sea surface and subsurface objects in MIL-STD-2525C do not have clear directions, so ground objects symbols were selected as substitutions to achieve the research purpose.

According to the U.S. military standard MIL-STD-2525C, the initial experimental materials were established, as shown in Figure 8.

In the experiment, three basic colors of LED display screen were selected from the HSV. They were blue $\left(\mathrm{H}=240^{\circ}, \mathrm{S}=100 \%\right.$, and $\left.\mathrm{V}=100 \%\right)$, green $\left(\mathrm{H}=120^{\circ}, \mathrm{S}=100 \%\right.$, and $\left.\mathrm{V}=100 \%\right)$, and red $\left(\mathrm{H}=0^{\circ}\right.$, $\mathrm{S}=100 \%$, and $\mathrm{V}=100 \%$ ), and they were named as "blue 2", "green 2", and "red 2", respectively. Subsequently, by reference of MCS color arrangement concept of equidistant Chroma and Value span, four colors were chosen randomly at the percentage changes of Saturation and Value on the basis of three basic colors before. There were 15 colors in total $(3+3 \times 4)$. All of the colors had been taken into calculation of color difference $(\Delta \mathrm{E})$, and the smallest $\Delta \mathrm{E}$ is 13.928, larger than $\Delta \mathrm{E}$ minimum identification value $3.3[54,55]$, making sure that there was enough distinctiveness for subjects to distinguish them. Figure 9a shows the color names and HSV values. As Lab color system has a more accurate transferability [56-58], all of the selected HSV format colors were converted into Lab format in this stage. Figure $9 \mathrm{~b}$ shows the colors Lab value. 


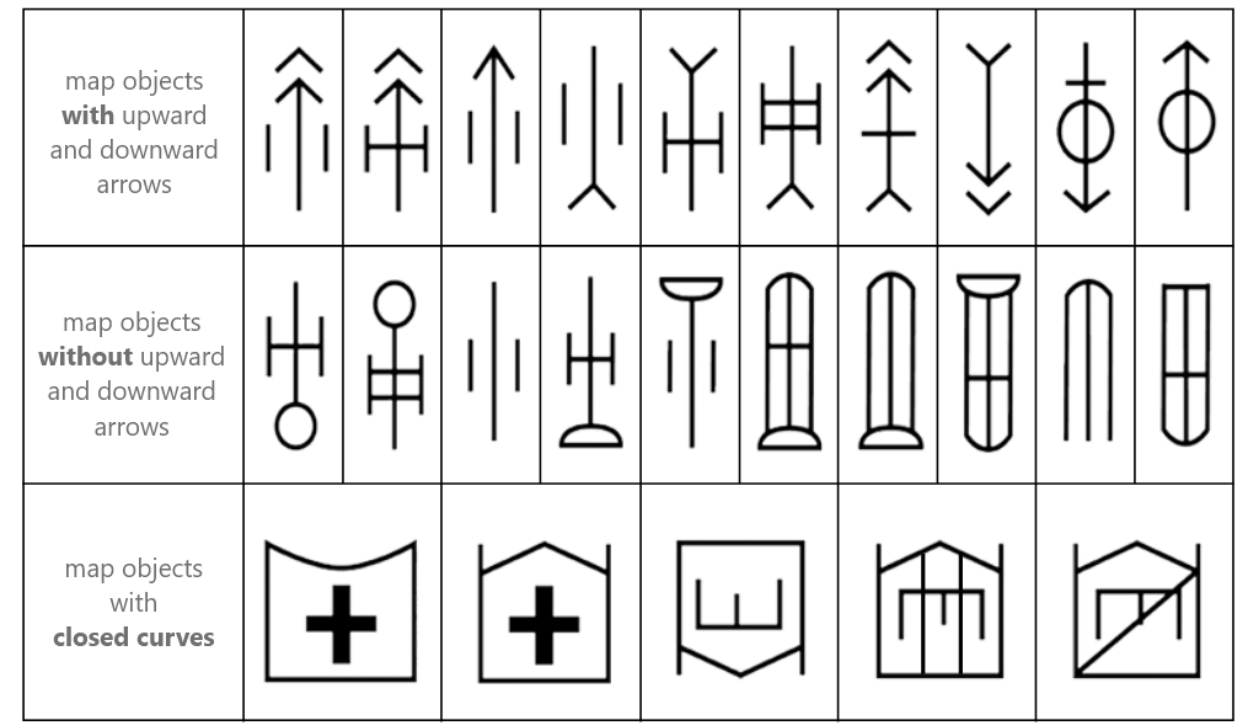

Figure 8. The initial experimental materials [28].

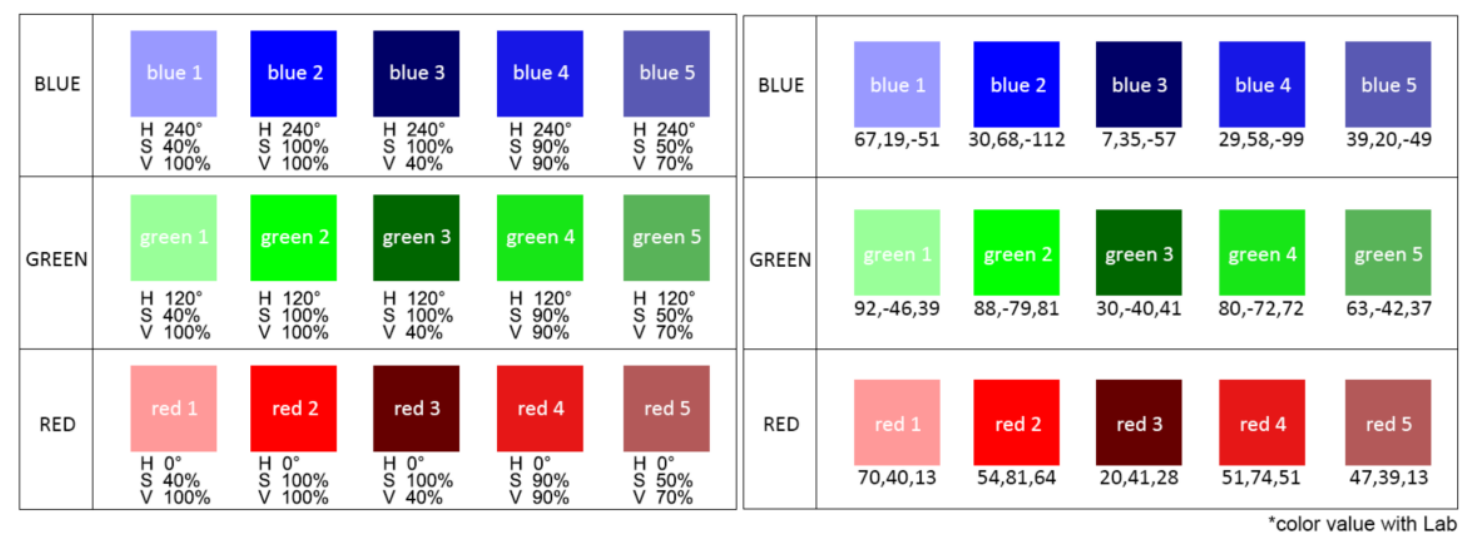

(a). The colors with HSV format. (b). The colors with Lab format.

Figure 9. The colors used in the experiment (The first line of $(\mathbf{a}, \mathbf{b})$ : blue 1, blue 2, blue 3, blue 4, blue 5; The second line of $(\mathbf{a}, \mathbf{b})$ : green 1 , green 2 , green 3 , green 4 , green 5 ; The third line of $(\mathbf{a}, \mathbf{b})$ : red 1, red 2, red 3 , red 4, red 5).

The terrain map of "Military Map" was used as the background of the experiment. In this type of map, the color of the ocean does not change with the change of depth. This experiment was conducted to obtain the searching time for military symbols, and eliminating the interference factors, such as small pieces of land on the map, is of great significance. Therefore, the background graph chosen for this experiment was designed to be a pure color-that is, blue for the ocean area of the terrain map. The standard topographic map was placed in the Illustrator software, using the straw tool to absorb the color of the ocean part and to fill the area of $1920 \times 1080$ pixels to make the experimental background. The Lab mode color value of blue used in background was $L=85, a=-10$, and $b=-23$, and Figure 10 shows the background. 

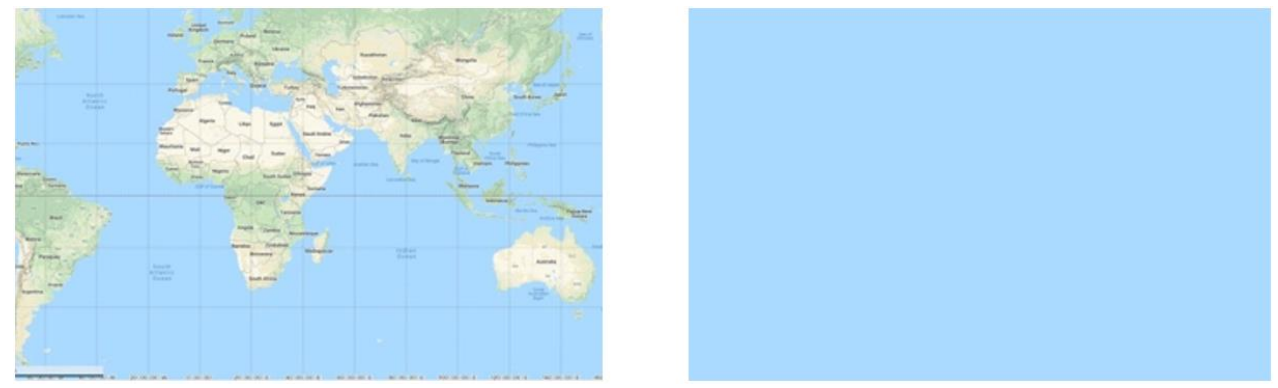

Figure 10. The experimental background extracted from the terrain map.

According to the suggestions in MIL-STD-1472, the size of the military symbols that are shown on the display can be calculated based on the following equation:

$$
\mathrm{L}=(\mathrm{VA}) \times(\mathrm{D}) /(57.3) \times(60),
$$

where VA is the perspective divided into units by arc, $\mathrm{D}$ is the visual distance in inches, and $\mathrm{L}$ is the object size in inches. Table 1 shows the reference data of the calculated size of the military symbols.

Table 1. Reference for the size of military symbols.

\begin{tabular}{cccc}
\hline D & VA= 20 arc & VA= 30 arc & VA= 40 arc \\
\hline 15 & 0.087 in. $(2.21 \mathrm{~mm})$ & 0.131 in. $(3.33 \mathrm{~mm})$ & 0.175 in. $(4.45 \mathrm{~mm})$ \\
20 & 0.116 in. $(2.95 \mathrm{~mm})$ & 0.175 in. $(4.45 \mathrm{~mm})$ & 0.233 in. $(5.92 \mathrm{~mm})$ \\
25 & 0.145 in. $(3.68 \mathrm{~mm})$ & 0.218 in. $(5.54 \mathrm{~mm})$ & 0.291 in. $(7.40 \mathrm{~mm})$ \\
30 & 0.175 in. $(4.45 \mathrm{~mm})$ & 0.262 in. $(6.65 \mathrm{~mm})$ & 0.349 in. $(8.87 \mathrm{~mm})$ \\
35 & 0.204 in. $(5.18 \mathrm{~mm})$ & 0.305 in. $(7.76 \mathrm{~mm})$ & 0.407 in. $(10.34 \mathrm{~mm})$ \\
40 & 0.233 in. $(5.92 \mathrm{~mm})$ & 0.349 in. $(8.87 \mathrm{~mm})$ & 0.465 in. $(11.82 \mathrm{~mm})$ \\
\hline
\end{tabular}

According to Table 1 and the documents in MIL-STD-1472, it is recommended to choose a larger size with 40 arc. This experiment was satisfied with this condition. In the experiment, the subjects' eyes were $600 \mathrm{~mm}$ away from the screen; $600 \mathrm{~mm}$ was converted to $24.62 \mathrm{in}$; and, by calculating the formula, the minimum length of the military symbols was determined to be $6.86 \mathrm{~mm}$. The military symbol materials used in this experiment were all scaled according to the shortest side length of $7 \mathrm{~mm}$, in accordance with MIL-STD-1472, which ensured that the subjects could clearly see the materials, as well as met the reasonable display size of symbols on the map.

\subsection{Experimental Process}

The subjects sat in a laboratory with soft light and noise isolation after washing and drying their hair. The lighting equipment are fluorescent lamps whose color temperature are all $6500 \mathrm{~K}$, which are consistent with the CIE D65 lighting criteria. After a subject had put on the clean electrode cap, conductive paste was injected into the gap between the electrode and the scalp. After all of the electrodes were energized, the stimuli were presented on a 21.5-in LED screen in front of the subject, the height of which was level with the subject's eyes. The subjects remained in a comfortable seated position with their eyes focused on the center of the screen, approximately $600 \mathrm{~mm}$ away from the screen. The stimuli appeared in the center of the screen with the observer angle of around 10-degree, and the display screen had been calibrated by "Datacolor Spyder 5 Elite" to make sure the color temperature is $6500 \mathrm{~K}$ and the color space is $100 \%$ sRGB, which assured that the visual experiment standard conformed to the CIE D65 standard [59]. Figure 11 describes the experimental scene. 


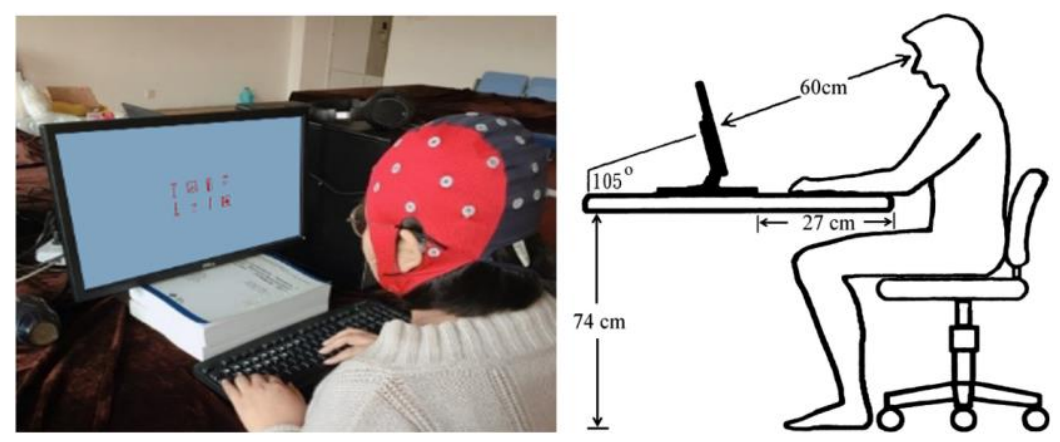

Figure 11. The electroencephalogram (EEG) experimental scene.

Before the formal experiment, the experimental contents and process were explained to the subject, and the criteria for judging the arrowheads were also explained. The interface of the stimuli was designed to show one of two states: one with directional arrow(s), where the orientation is only up and down; the other without any directional arrows. If the subject did not observe the arrowhead, they responded by pressing the space bar. In contrast, if they did observe an arrowhead, they had to quickly determine the direction of the arrowhead and press either the " $\mathrm{A}$ " key, representing up, or the "Z" key, representing down. During the practice period, the subject was informed regarding whether their reactions were correct or not, and ten practice experiments were conducted for training. After the subject fully understood the experimental task, they entered the formal experiment.

The experiment was designed using and presented by E-Prime 2.0. The experiment consisted of three different color series, namely, blue, green, and red. Taking the blue series as an example, it contained five kinds of blue selected from the MCS according to different Chroma and Value, which were divided into blue 1 , blue 2 , blue 3 , blue 4 , and blue 5 . Each color contained 30 picture stimulations and there was a total of $3 \times 5 \times 30=450$ trials of the 15 colors in the whole experiment. In other words, each subject had to complete 450 trials, and 450 trials were divided into three rounds of experiments with 150 trials in each round.

The experimental materials with different colors of red, green, and blue Hues appeared alternately and randomly in order to avoid the learning effect generated in the experiment. Namely, the red, green, and blue stimuli all appeared in every 150 trials, among which, 50 trials occurred randomly for each Hue. For each round of the experiment, the system suspended the playing of the stimuli, so that the subjects could have a sufficient period of time to relax and rest. Avoiding excessive fatigue or psychological boredom can ensure the objective validity of the experimental data. The entire experiment took about $40 \mathrm{~min}$. (including rest) for each subject.

The P300 component is always evoked through classic Oddball experiment paradigm or other paradigms, such as learning-recognition paradigm, cue-prompt paradigm, and so on, because it is a complex EEG component that is related with most cognition process. This article adopted improved learning-recognition paradigm, and recognition targets had been displayed to subjects to learn and memorize before the formal experiment.

Figure 12 shows the experimental process of a single trial. Each trial consisted of three steps. Step 1: the screen presented a cross fixation point in the center of a blue background with the same Lab mode color value (i.e., 85, $-10,-23$ ). This screen lasted for $500 \mathrm{~ms}$, reminding the subject to look toward the central area of the screen. Step 2: a stimulating screen appeared in the middle of the screen, the background color of which was of the same Lab mode color value as Step 1 (i.e., 85, $-10,-23$ ). The size of the short side a single military symbol was $7 \mathrm{~mm}$. The subjects made corresponding choices on the keyboard according to the military symbols that they observed. In other words, they pressed A when observing one or more military symbols with an up arrow, while pressing $\mathrm{Z}$ for down arrows and Space for no arrows. Step 3: after pressing the button, an empty blue (i.e., 85, -10, -23) screen interface with a duration of $500 \mathrm{~ms}$ appeared to help the subjects eliminate temporary visual retention. 
The reason for choosing the blue screen was to avoid excessive contrast between the stimuli screen and the transition screen, which may affect the physiological adjustment of the subject's eyes.

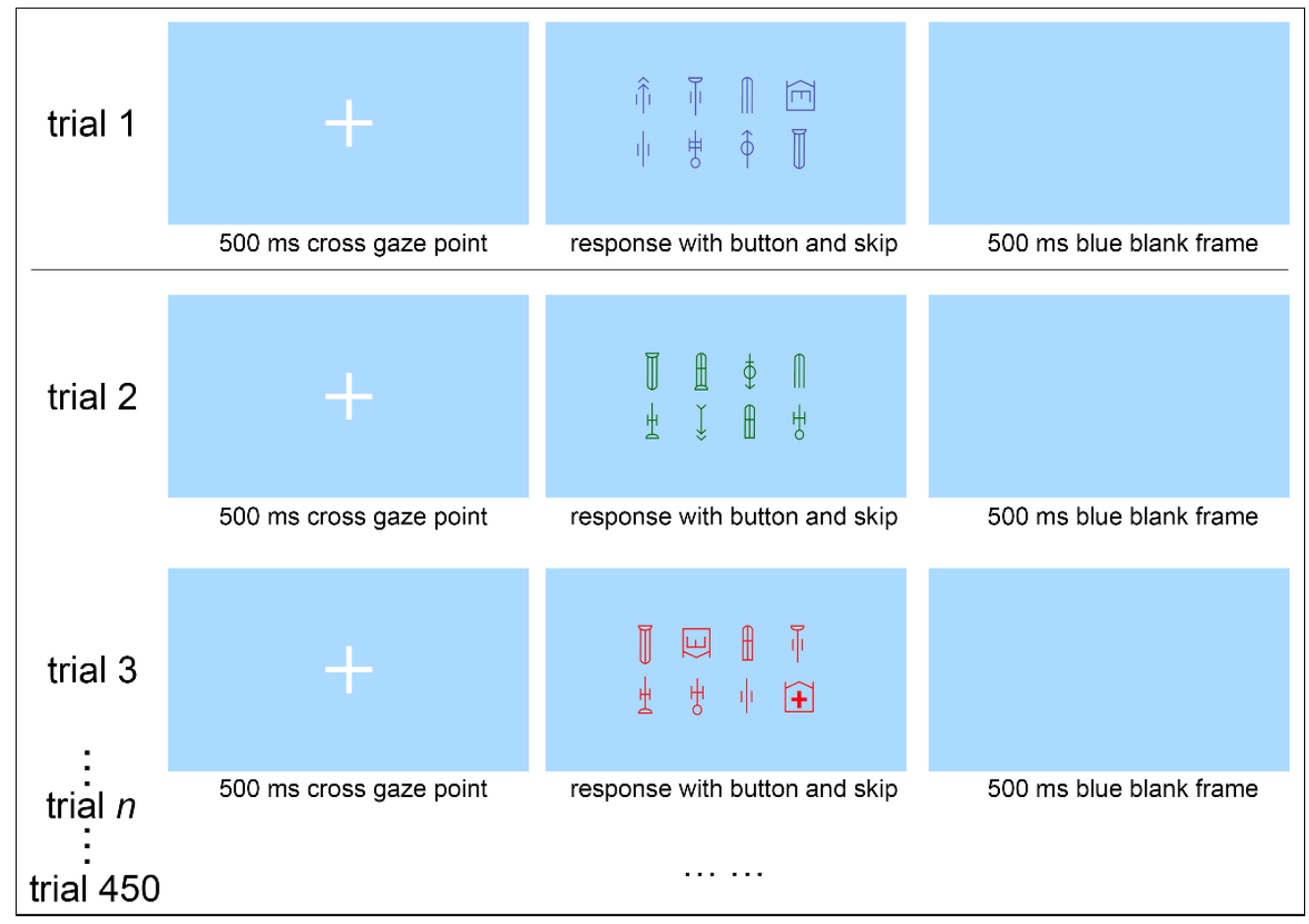

Figure 12. Experimental process.

\subsection{Hypothesis}

According to the study of the P300 component in ERP by Wei et al. [39], together with the important theory proposed by Kutas et al., there is a solid correlation between the P300 component and the amount of human mental resources occupied. That is to say, the amplitude of the P300 component is positively correlated with the mental resources occupied in operation [21]. In other words, the greater the absolute value of the amplitude of P300, the more human mental resources occupied by the event, which means the greater the task load for human beings. On the contrary, the smaller the value of P300, the less mental resources occupied, and the lower the operation load, the more relaxed users feel [23]. Niu et al. further verified this in an ERP study of icon memory under time pressure: the amplitude of P300 increases with the increase of task difficulty and the latency of P300 is negatively correlated with task difficulty [24].

Based on the theoretical support above, in this experiment, with stimuli of different colors, the collected P300 amplitude and latency should be presented with alienation. Two indicators can reflect the mental resource usage brought by the different colors of the symbols, identifying load differences in the task. By analyzing P300, combining the accuracy and reaction time in the behavioral data, it is expected that the relationship between the merits and demerits of the colors of military symbols used for the interface of maps can be obtained. The following experimental results are expected in this paper:

- Military symbols that induce P300 with a large amplitude and a long latency occupy more cognitive resources, while P300 with a small amplitude and a short latency occupy less cognitive resources.

- Military symbols with high Value have poor color recognition, and their performance are lower than the average level. Military symbols with low Chroma and medium Value are more recognizable and have better performance. 


\section{Results and Data Analysis}

\subsection{Behavioral Data}

The behavioral data refers to the two indicators of accuracy and reaction time. Accuracy refers to the proportion of the correct number of buttons in relation to the total number of stimuli. In other words, accuracy = "the correct number of keys"/"the total number of stimuli". Reaction time refers to the time between the moment the subject sees a stimulus and the moment they respond by pressing a button. In this experiment, the unresponsive data of the subjects were regarded as invalid data, and the accuracy and reaction time data in E-Prime were exported. After processing and analyzing the experimental data with Excel and SPSS software, the mean accuracy and the mean reaction time values of the 15 colors in $3 \times 5$ groups were calculated, and the results show that the lowest accuracy of the 15 colors was $96.4 \%$ in blue 1 , while the highest was $99.3 \%$ in green 2 , and the average accuracy was around 98\%, as shown in Figure 13.

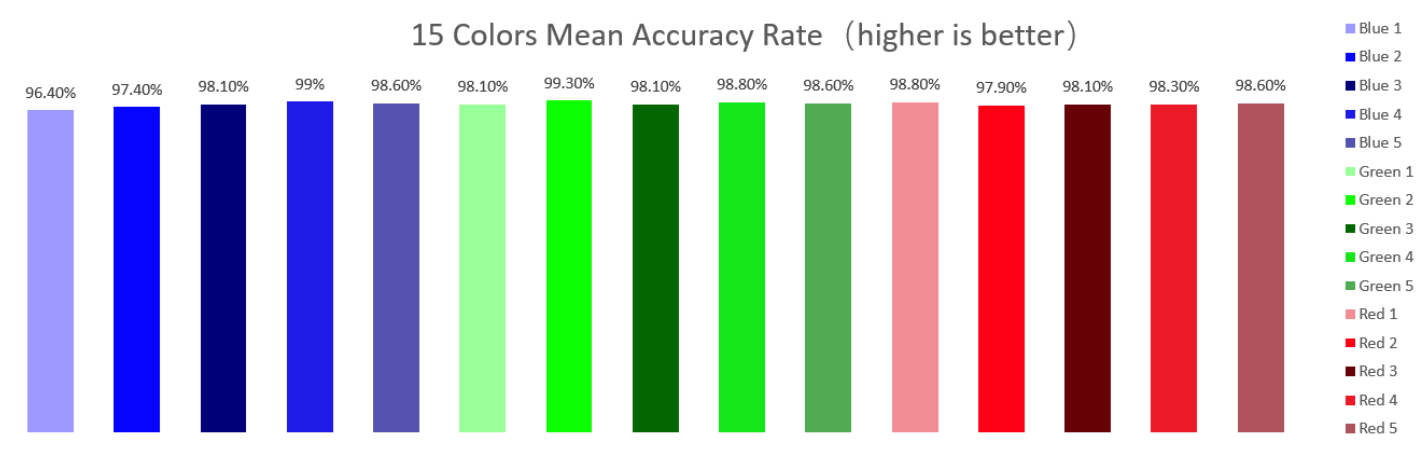

Figure 13. Mean accuracy of the 15 colors in the behavior experiment.

The 15 colors were classified into red, green, and blue series, and reaction time data were sorted, as shown in Figure 14. In the blue series, the reaction time of blue 1 was the longest, with an average of $1712 \mathrm{~ms}$, while that of blue 5 was the shortest, with an average of $1044 \mathrm{~ms}$. Among the green series, the reaction time of green 1 was the longest, with an average of $1444 \mathrm{~ms}$, while that of the green 5 was the shortest, with an average of $948 \mathrm{~ms}$. In the red series, the reaction time of the red 1 was the longest, with an average of $1025 \mathrm{~ms}$, while that of red 4 was the shortest, with an average of $836 \mathrm{~ms}$.
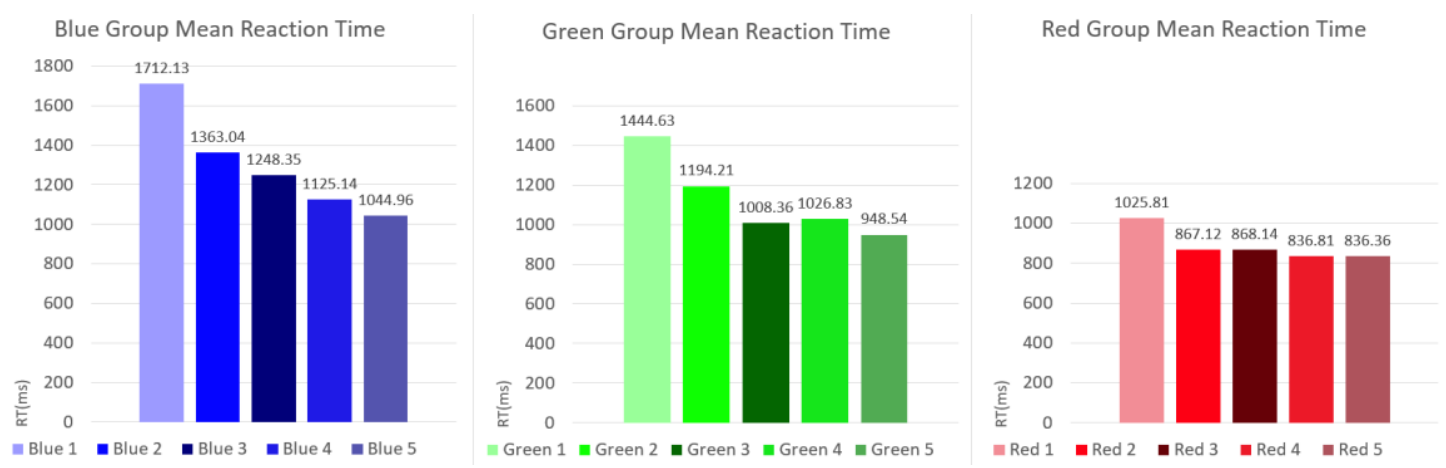

Figure 14. Average reaction time of the subjects in the blue behavior experiment.

\subsection{EEG Data}

Before the numerical processing of EEG data, the ophthalmic artifacts were first identified and then removed by the filtering function of the ASA software, and then the original EEG waves that were obtained in the target search experiment were segmented. The target stimuli (i.e., the images) were taken as the baseline for segmentation, beginning from $200 \mathrm{~ms}$ before presentation of the stimuli 
to $600 \mathrm{~ms}$ after presentation. Subsequently, the EEG waves of each subject were superimposed and averaged. After that, the EEG waves of all subjects were averaged and sorted into the 15 different colors.

\subsubsection{Blue Series}

Firstly, the amplitude of P300 was analyzed, and the absolute values of the average amplitude of each color in the blue series followed the order of: blue $4(4.237 \mu \mathrm{V})>$ blue $2(3.618 \mu \mathrm{V})>$ blue 5 $(3.483 \mu \mathrm{V})>$ blue $1(3.417 \mu \mathrm{V})>$ blue $3(3.196 \mu \mathrm{V})$.

P300 generally occurs in the parietal lobe. In this study, P3, P4, CP1, CP2, Pz, and POz were chosen based on the selection of electrodes in the experimental study of P300 conducted by our predecessors [24,41,42] and the significance of the amplitude of each electrode in the EEG.

Subsequently, a repeated ANOVA of 5 (blue: blue 1 , blue 2, blue 3 , blue 4 , and blue 5 ) $\times 6$ (electrode: P3, P4, Pz, CP1, CP2, and POz) was conducted for P300 amplitude. It can be seen that the main effect of the color blue is significant, $\mathrm{F}=3.592, p=0.007<0.05$, and the main effect of the electrode is significant, $\mathrm{F}=43.969, p=0.000<0.05$, while the interaction between the two is not significant, $\mathrm{F}=0.269, p=0.999$.

The six electrodes can be divided into the left side (i.e., P3 and CP1), the middle side (i.e., Pz and POz), and the right side (i.e., P4 and CP2). A repeated ANOVA of 5 (blue: blue 1, blue2, blue3, blue4, and blue 5) $\times 3$ (brain area: left, middle, and right) was conducted, and it is clear that the main effect of the color blue is significant, $\mathrm{F}=3.700, p=0.006$, the main effect of the brain area is significant, $\mathrm{F}=5.116$, $p=0.007$, while there is no significant interaction between the two, $\mathrm{F}=0.272, p=0.975$.

A paired t-test of the different groups of blue subjects in the different brain areas showed that, in the left-brain area, the subjects showed significant differences in the brain wave amplitude of the blue symbols. The paired t-test of the left-brain area showed that the effect of the P3 electrode was significant; thus, the P3 electrode could be used as the key electrode. According to the amplitude map on the P3 electrode, it can be found that there is no significant difference in the time of P300 in the five different blue colors, as shown in Figure 15.

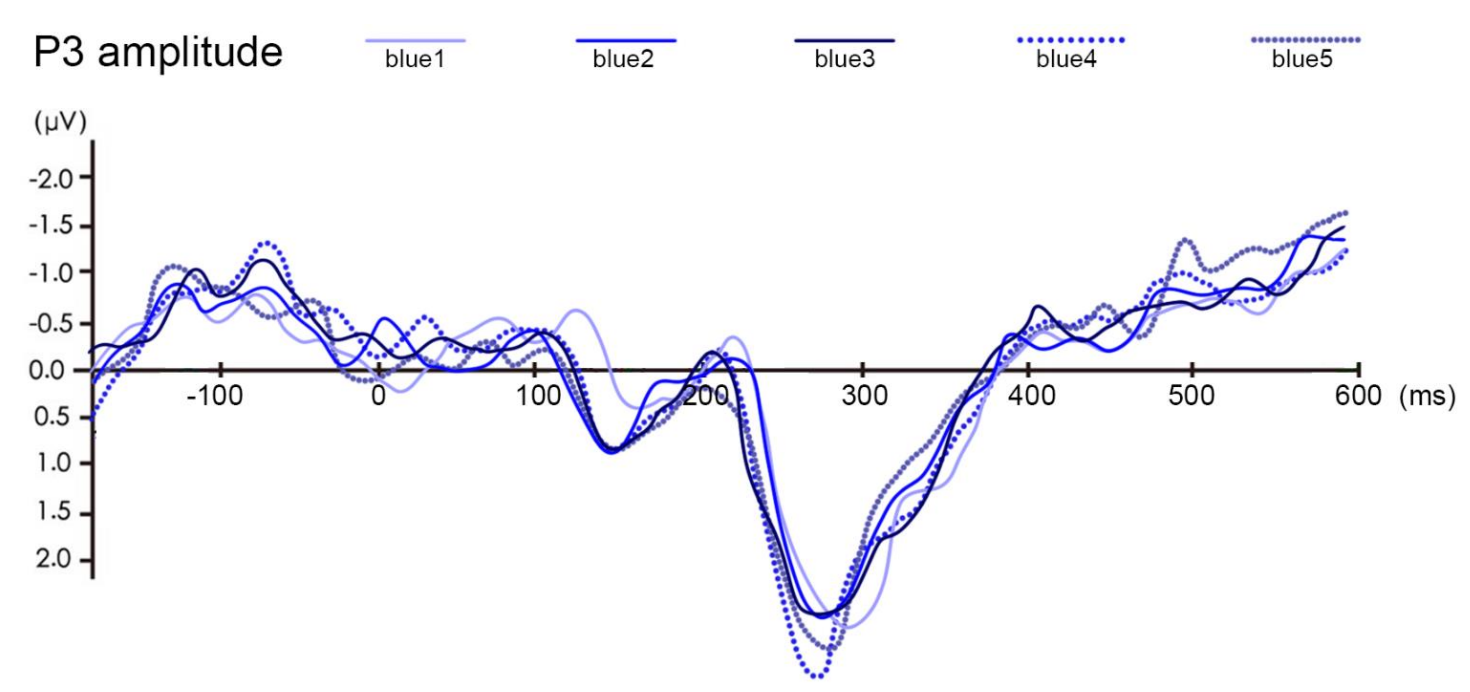

Figure 15. Comparison of the five different blues in terms of the P300 amplitude in the P3 electrode.

Latency analysis was carried out on the blue group. In the target search experiment, P300 latency has the following relationship: blue $3(0.301 \mathrm{~s})>$ blue $4(0.293 \mathrm{~s})>$ blue $2(0.283 \mathrm{~s})>$ blue $1(0.279 \mathrm{~s})>$ blue 5 (0.27 s).

A multiple factor repeated ANOVA of 5 (blue: blue 1, blue 2, blue 3, blue 4, and blue 5 ) $\times$ 6 (electrode: $\mathrm{P} 3, \mathrm{P} 4, \mathrm{Pz}, \mathrm{CP} 1, \mathrm{CP} 2$, and $\mathrm{POz}$ ) was conducted for the latency. It can be seen that the main effect of the color blue is not significant, $\mathrm{F}=1.377, p=0.242$, while the main effect of the electrode is 
significant, $\mathrm{F}=7.721, p=0.000<0.05$, and the interaction effect of the two is not significant, $\mathrm{F}=0.824$, $p=0.684$.

\subsubsection{Green Series}

Firstly, the absolute value of the average amplitude of each color was analyzed according to the P300 amplitude. The mean amplitude of each color followed the order of: green $5(4.609 \mu \mathrm{V})>$ green 1 $(3.367 \mu \mathrm{V})>$ green $2(3.200 \mu \mathrm{V})>$ green $3(2.495 \mu \mathrm{V})>$ green $4(2.656 \mu \mathrm{V})$.

A repeated ANOVA of 5 (green: green 1, green 2, green 3 , green 4 , and green 5$) \times 6$ (electrode: P3, $\mathrm{P} 4, \mathrm{Pz}, \mathrm{POz}, \mathrm{CP} 1$, and $\mathrm{CP} 2$ ) for the amplitude was carried out. It can be seen that the main effect of the color green is significant, $\mathrm{F}=3.374, p=0.010<0.05$, and the main effect of the electrode is significant, $\mathrm{F}=12.119, p=0.000<0.05$, while the interaction between the two is not significant, $\mathrm{F}=0.465, p=0.978$.

A paired $t$-test of the different green targets in the different brain areas showed that, in the leftand middle-brain areas, the subjects showed significant differences in the brain wave amplitude of the green target and greater differences in the left-brain areas. Subsequently, a paired $t$-test of the CP1 and P3 electrodes was conducted, and it can be concluded that the P300 amplitude that is caused by the green targets has the largest difference on the P3 electrode; thus, the P3 electrode can be taken as the key electrode, as shown in Figure 16.

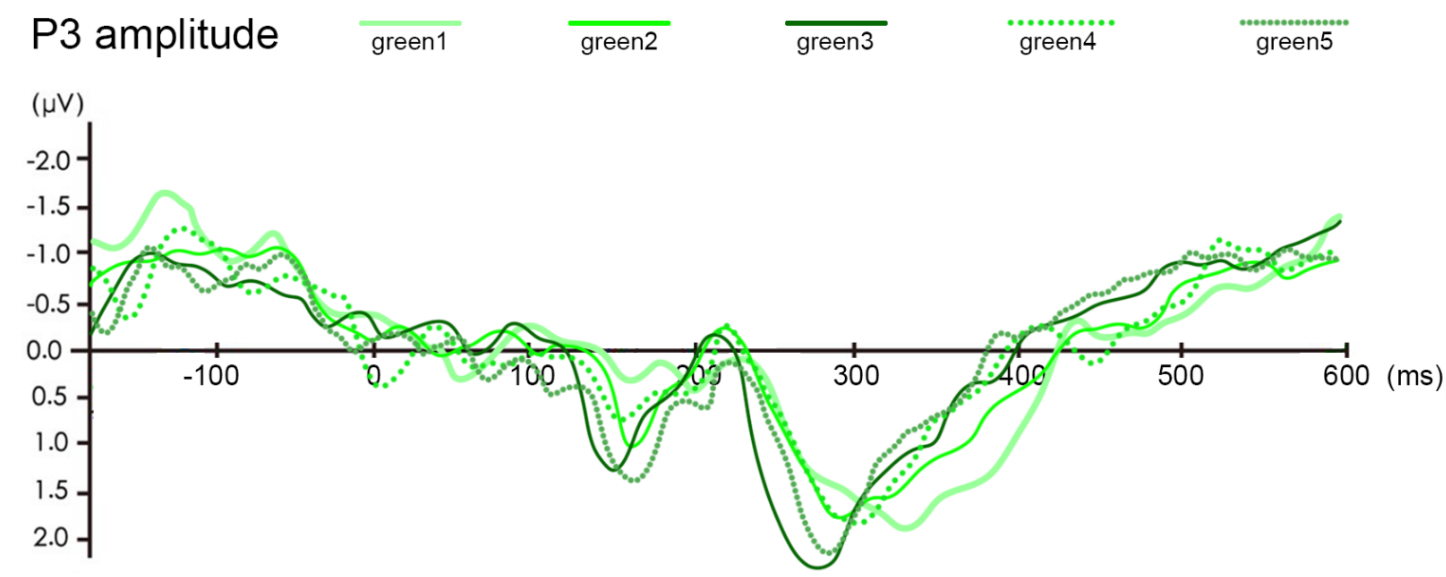

Figure 16. Comparison of the five different greens in terms of the P300 amplitude in the P3 electrode.

According to the amplitude map of the P3 electrode, the time of P300 that appeared in five kinds of green has some differences. Among them, a big difference can be observed between green 3 and green 1 and, thus, the change of the latency of green 3 and green 1 was focused on.

The latency of the different green colors was analyzed. In the target search experiment of the green symbols, the P300 latency has the following relationship: green 2 (0.371 s) > green $5(0.362 \mathrm{~s})>$ green $1(0.358 \mathrm{~s})>$ green $4(0.354 \mathrm{~s})>$ green $3(0.354 \mathrm{~s})$.

A repeated ANOVA was carried out for 5 (green: green 1 , green 2 , green 3 , green 4 , and green 5 ) $\times$ 6 (electrode: P3, P4, Pz, P7, P8, and POz) for the P300 latency. It can be seen that the main effect of the color green is not significant, $\mathrm{F}=1.539, p=0.191$, while the main effect of the electrode is significant, $\mathrm{F}=5.287, p=0.000<0.05$, and the interaction between the two is not significant, $\mathrm{F}=0.944, p=0.532$.

\subsubsection{Red Series}

Firstly, based on the analysis of the P300 amplitude, the mean amplitude of each color in the red series followed the order of: red $(2.813 \mu \mathrm{V})>\operatorname{red} 1(2.698 \mu \mathrm{V})>\operatorname{red} 5(2.674 \mu \mathrm{V})>\operatorname{red} 2(2.557 \mu \mathrm{V})>$ red $3(2.488 \mu \mathrm{V})$.

A repeated ANOVA of 5 (red: red 1, red 2, red 3, red 4, and red 5) $\times 6$ (electrode: P3, P4, Pz, CP1, $\mathrm{CP} 2$, and POz) for the P300 amplitude was conducted. It can be seen that the main effect of the color 
red is not significant, $\mathrm{F}=1.431, p=0.224$, while the main effect of the electrode is significant, $\mathrm{F}=44.397$, $p=0.000<0.05$, and the interaction between the two is not significant, $\mathrm{F}=0.373, p=0.989$.

A paired $t$-test of the different red targets in the different brain areas showed that, in the middle brain areas, the subjects showed significant differences in the brain wave amplitude of the red symbols. Subsequently, a paired $t$-test of the POz and Pz electrodes was conducted, and it can be concluded that the P300 amplitude caused by the red target has the largest difference on the Pz electrode; thus, the Pz can be taken as the key electrode, as shown in Figure 17.

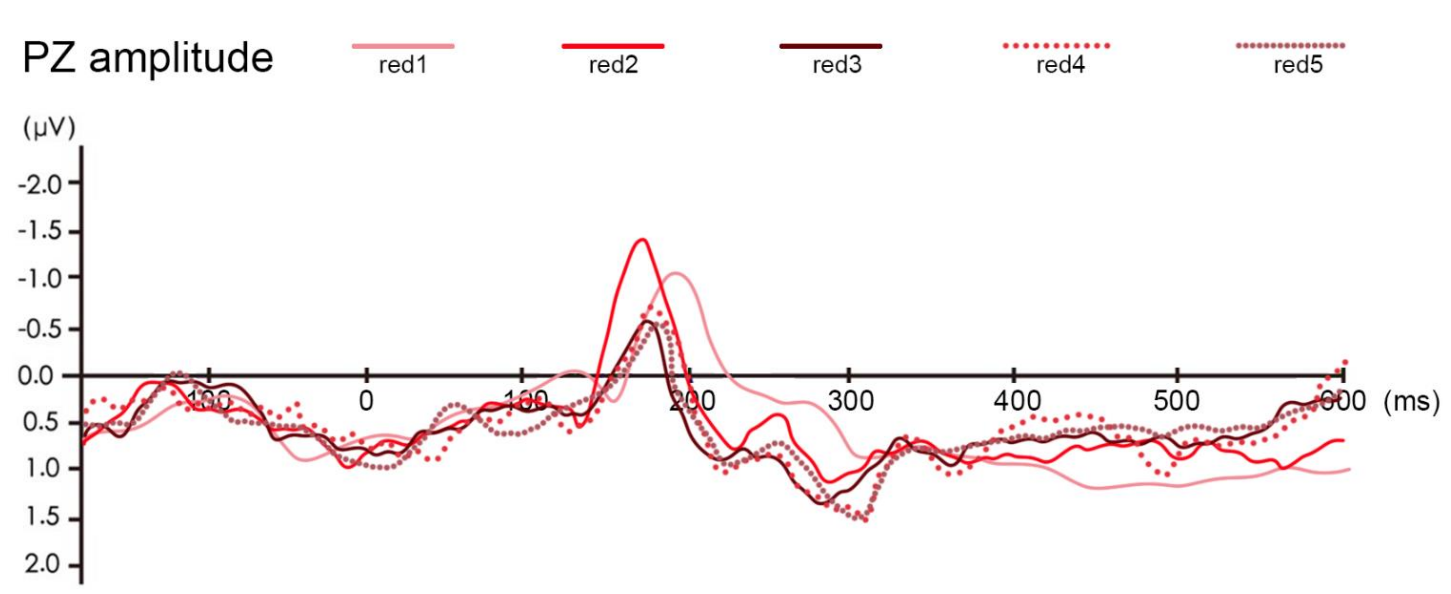

Figure 17. Comparison of the five different reds in terms of the $\mathrm{P} 300$ amplitude in the Pz electrode.

For the red group, the latency of P300 followed the order of: red $1(0.358 \mathrm{~s})>\operatorname{red} 2(0.357 \mathrm{~s})>$ red $3(0.356 \mathrm{~s})>$ red $5(0.347 \mathrm{~s})>$ red $4(0.345 \mathrm{~s})$ in the target search experiment.

A repeated ANOVA was conducted of 5 (red: red 1, red 2, red 3, red 4, and red 5) $\times 6$ (electrode: P3, P4, Pz, P7, P8, and POz) for the P300 latency. It can be seen that the main effect of the red color is not significant, $\mathrm{F}=1.142, p=0.337$, while the main effect of the electrode is significant, $\mathrm{F}=4.907$, $p=0.000<0.05$, and the interaction between the two is not significant, $\mathrm{F}=1.180, p=0.271$.

\section{Discussion}

\subsection{Behavior Experiment}

According to the histogram of the accuracy of the 15 colors, there are no significant differences among the different colors, and the values are all greater than $96 \%$-i.e., close to 1 -indicating that the task is of low difficulty, which was not able to directly reflect the relationship between the merits and disadvantages of the colors of the different military symbols. Thus, the reference value of accuracy data is poor.

As can be seen from Figure 14, in the blue series, blue 1 had the longest reaction time in the cognitive experiment, which differed considerably from the other four blue colors. Blue 2, blue 3 , blue 4 , and blue 5 showed little difference in reaction time, among which blue 5 showed the lowest reaction time, which indicated that blue 5 had the best performance in the blue series. In the green series, green 1 had the longest reaction time, followed by green 2 . There were no significant differences in the response times between green 3 , green 4 , and green 5 , among which green 5 showed the lowest reaction time and best performance within the green series. In the red series, red 1 had the longest reaction time in the cognitive experiment, while the red 2 , red 3 , red 4 , and red 5 had little differences in reaction times, among which red 4 and red 5 had the lowest reaction times and the best performance.

Comparing the three colors with the serial number 1 (i.e., blue 1, green 1, and red 1), they are all high value colors in the MCS, and they all had a longer reaction time compared to the other colors of the same Hue. In the study of Chen et al. on the processing speed of color information, a similar result was found; that is, the value of the color affected the cognitive processes of the users, and the time 
point of this influence was later than the Hue of the color itself [60]. It can be seen that, in sea situation maps, the use performance of high value colors is poor, as is the readability; thus, high value color symbols should be avoided as much as possible in the design of a map.

It is also worth noting that the average reaction time of the blue series was longer than that of the green series, and the average reaction time of the green series was longer than that of the red series. The potential reasons are as follows: (1) the experimental background is the sea surface map, which is a pure blue color itself, so the difference between the blue military symbols and background in the experiment is not obvious enough, resulting in the long reaction time of the subjects in the behavioral experiment. It is suggested that colors with less difference between the target and the background should be avoided when using colors in the interface of a map. (2) The reaction time of the red series is significantly lower than that of the other two colors, which is related to the fact that the longer red wavelength is more likely to attract visual attention. In addition, in people's daily lives, the potential awareness of red has a warning effect [52], which may eventually lead to a red target being able to easily arouse users' stronger perceptions and reactions. It is suggested that, when designing colors for the interface of a map, under certain circumstances, such as to indicate dangerous objects, a red color is preferred. At the same time, the usage criteria of colors, such as red and blue, may be specific and different worldwide. Red color is used to represent enemy units in America while being used to symbolize the own side in China and Russia. When applying such colors, it is suggested that designers should take all rules and situations into consideration carefully.

\section{2. $P 300$}

In the EEG experiment, P300 was selected as a typical component for analysis, which is often used for analysis in fields, such as neuro-cognition and neuro-design. For example, in a group of experiments on the influence of color on cognition, Hasan et al. applied and analyzed the classical P300 components [61]. In this paper, P300 was selected in accordance with the mainstream evaluation methods in the field. According to the suggestions of many researchers [62-64], the average amplitude of P300 increases with the increase of attention resources, which was the general basis for the evaluation and selection of the best color in this experiment.

The five different blue colors all caused P300 potentials, mainly in the right hemisphere of the brain. The paired $t$-test showed that the amplitude of the P3 electrode had a significant influence on the other electrodes. In the EEG study of color matching tasks that was conducted by Shou and Ding, the P3 electrode was also chosen for research further due to its amplitude change, and it was finally concluded that the observed reduction of the P3 amplitude was related to the semantic conflict in the color matching process [65], which was significantly consistent with the P3 electrode obtained in this paper. In this experiment, the amplitude and latency of the five different kinds of blue did not show any abnormal differences, while the main effects were obvious, which can explain how much visual attention space is occupied by different colors. As can be seen from the amplitude, blue 3 occupies the least cognitive resources, followed by blue 1 , while blue 4 occupies more cognitive resources.

The five different green colors all generated P300 potential components, being mainly distributed in the left-brain area. The waveforms that were caused by the five green colors were similar, with no obvious abnormalities, while the main effects were obvious, indicating how much visual attention space is occupied by different colors. Among them, the P300 amplitude of the green 4 group is small and the latency is short, indicating that green 4 color has a relatively small mental load and has a better advantage. However, the P300 produced by green 1 and green 5 has a large amplitude and long latency, which takes up a lot of mental resources, and is not recommended when it comes to color matching in the interface of a map.

The five different red colors all evoked P300 potential components, mainly located in the medial-brain area. In the paired $t$-test, the P300 component amplitude that was caused by the red group was mostly significant on the Pz electrode. Yeh et al. proposed that color combination target stimulation has significant effects on the central C3 and CZ and the parietal P3, Pz, and P4 electrodes [28], which is 
consistent with the significant electrodes shown in this paper. Among them, red 3 has the smallest amplitude, which shows that it takes up less cognitive resources and is an optimal choice. However, the amplitude and latency of red 1 are both lower than the average level of the group; thus, red 1 is not recommended for designing symbols for use in the interface of a map.

However, the findings above on P300 should be treated with caution due to some problems with this measurement method. For example, the imprecision of EEG waveform analysis and the small differences caused by the average difficulty of tasks will lead to errors in P300 component analysis [66]. In addition, Wicke et al. found that ERP may change with the change of brightness of a stimulus. The higher the brightness, the shorter the latency, and the brightness difference that is generated by the screen luminescence principle has a potential impact on the experiment [67].

In addition, the optimal color sequence derived from the behavioral data does not necessarily conform to the recommendations resulting from the EEG results. Ecker used EEG to study colors and concluded that the results related to ERP indicators could not be explained by basic differences in behavioral performance [68]. This is potentially related to the semantic differences that are brought by different colors. The material in this experiment was based on military symbols in the battlefield environment. Green, blue, and red are given different semantics by different subjects with different personal experiences, resulting in individual differences. Gan et al. used ERP technology to study whether different colors have an impact on moral-related words. The results showed that, when people judge immoral words, green words take longer than red or blue words. Thus, it is inferred that the metaphorical connection between green and moral information results in different information processing times presented by ERP in comparison to the experimental results of behavioral analysis [69]. Therefore, this paper proposes a sorting method that takes the data of EEG as the main reference index and the behavioral data as the secondary reference index in order to select the best color.

\subsection{Color Sorting and Selecting Method}

From the perspective of color matching optimization and cognitive theory, the optimization relationship of the experimental data under each color matching method is as follows: the smaller the amplitude of $\mathrm{P} 300$, the better the color; the shorter the latency of P300, the better the color; the shorter the reaction time, the better the color; and, the higher the accuracy, the better the color. The 15 colors were divided into three groups according to Hue, and the five colors in each group were ranked from good to bad according to four different indexes of the experimental data.

Figure 18 shows the ranking of the four indexes of the blue colors. The arrangement from left to right indicates the relationship from good to bad. In the process of optimizing, the ranking of two indexes of P300 were firstly averaged, such as blue 5, which ranks third in P300 amplitude with "fair" and first in P300 latency with "best"; thus, the blue 5 P300 component ranking is "good". The rest can be carried out in the same manner. It is established that the ranks of blue 1 and blue 5 are parallel with the grade "good". By comparing the reaction times of blue 1 and blue 5 , it can be observed that blue 5 has a better performance. As a result, blue 5 is given optimization from the blue series. Figure 19 shows the optimizing process.

\begin{tabular}{lccccc}
\hline BLUE Ranking & best & good & fair & limited & poor \\
\hline P300 Amplitude & blue 3 & blue 1 & blue 5 & blue 2 & blue 4 \\
\hline P300 Latency & blue 5 & blue 1 & blue 2 & blue 4 & blue 3 \\
\hline Reaction Time & blue 5 & blue 4 & blue 3 & blue 2 & blue 1 \\
\hline Accuracy Rate & blue 4 & blue 5 & blue 3 & blue 2 & blue 1 \\
\hline
\end{tabular}

Figure 18. Color ranking of the blue series with four indexes. 


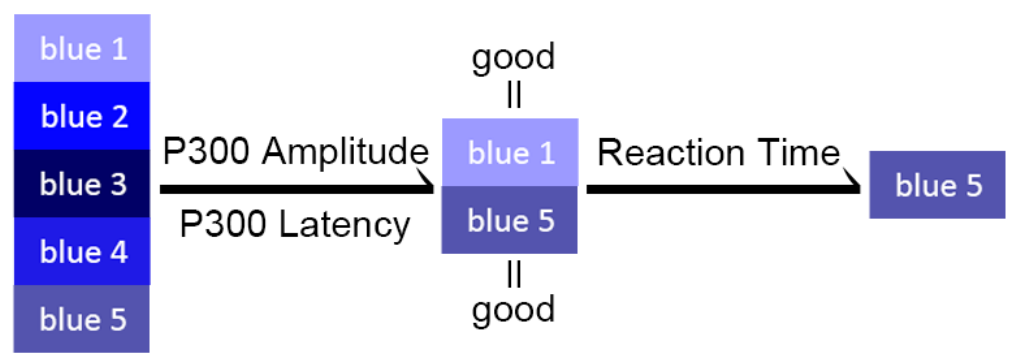

Figure 19. Blue optimization process.

Figure 20 shows the ranking of the four indexes of the green colors. With the same method used in the blue series, it is determined that green 3 and green 4 have the same grade, which is between "best" and "good". Furthermore, the ranking of green 4 in the reaction time is better than that of green 3; thus, green 4 is selected as the best in the green series. Figure 21 shows the optimizing process.

\begin{tabular}{lccccc}
\hline GREEN Ranking & best & good & fair & limited & poor \\
\hline P300 Amplitude & green 4 & green 3 & green 2 & green 1 & green 5 \\
\hline P300 Latency & green 3 & green 4 & green 1 & green 5 & green 2 \\
\hline Reaction Time & green 5 & green 4 & green 3 & green 2 & green 1 \\
\hline Accuracy Rate & green 2 & green 4 & green 5 & green 3 & green 1 \\
\hline
\end{tabular}

Figure 20. Color ranking of the green series with four indexes.

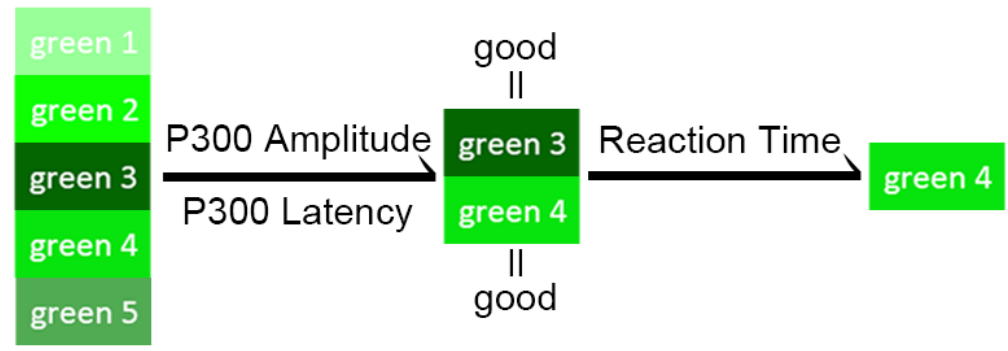

Figure 21. Green optimization process.

Figure 22 shows the ranking of the four indexes of the green colors. With the same method used above, it is concluded that red 3 ranks "good", while red 5 ranks between "fair" and "good", which means that red 3 is better than red 5 in the P300 averaged index. In accordance with the principle of EEG research priority, which no longer uses sorting of behavioral data, red 3 is selected as the best in the red series. The optimizing process is shown in Figure 23.

To sum up, blue 5 is selected as the optimal color in the blue series, with a Lab value of $L=39$, $a=20$, and $b=-49$. In the green series, green 4 is selected as the optimal color, with a Lab value of $\mathrm{L}=80, \mathrm{a}=-72$, and $\mathrm{b}=72$. In the red series, red 3 is selected as the optimal color, with a Lab value of $\mathrm{L}=20, \mathrm{a}=41$, and $\mathrm{b}=28$. 


\begin{tabular}{|c|c|c|c|c|c|}
\hline RED Ranking & best & good & fair & limited & poor \\
\hline P300 Amplitude & red 3 & red 2 & $\operatorname{red} 5$ & red 1 & red 4 \\
\hline P300 Latency & red 4 & red 5 & $\operatorname{red} 3$ & red 2 & $\operatorname{red} 1$ \\
\hline Reaction Time & red 5 & $\operatorname{red} 4$ & red 2 & $\operatorname{red} 3$ & $\operatorname{red} 1$ \\
\hline Accuracy Rate & red 1 & red 5 & red 4 & red 3 & $\operatorname{red} 2$ \\
\hline
\end{tabular}

Figure 22. Color ranking of the red series with four indexes.

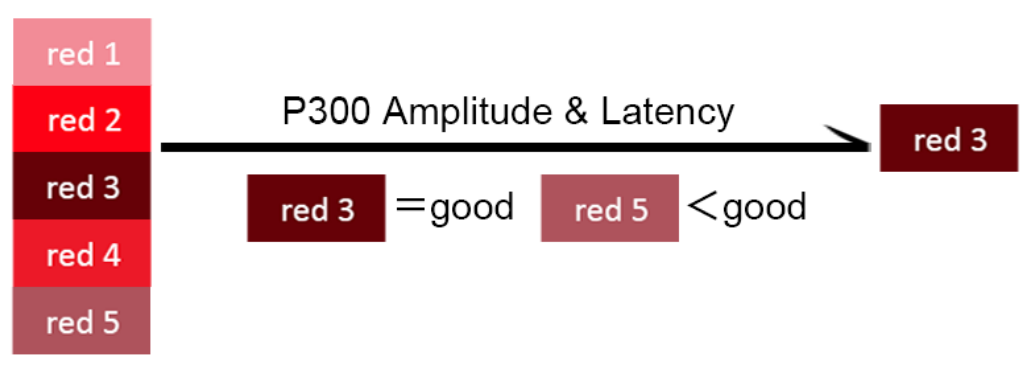

Figure 23. Red optimization process.

\section{Verification Experiment Based on the NASA-TLX Scale}

The NASA-TLX scale is often used to evaluate the physiological and mental burdens of users when they are doing a specific task, thus reflecting the difficulty and load of said task [70]. It consists of six dimensions, namely, mental demand (MD), physiological demand (PD), time demand (TD), effort level (EL), performance level (PL), and frustration level (FL). After the users have completed a task, they fill in this scale according to their own subjective feelings according to the six dimensions. The scale bar on the left side represents low task load, while the right side of the bar represents high task load. According to the research requirements, scoring methods, such as seven levels, order 9 levels, or 100 points can be set. The smaller the value, the lower the user load it represents; the larger the value, the higher the user load it represents.

The subjects of this verification experiment were postgraduates or undergraduates of the Southeast University, including 15 males and 15 females. All of the subjects were aged between 22 and 27, with an average age of 24.3. The standard deviation of the subjects' age was 1.135. No subjects were color blind or weak, all were right-handed, and all were expert users familiar with GIS systems.

Applying the selected blue 5, green 4, and red 3 to the color design of the interface of a map of military symbols, three map interfaces with different military symbols were drawn while using the Illustrator software. The blue one was then taken as an example, as shown in Figure 24.

In the verification experiment, 30 subjects were required to complete two tasks. In first task, subjects were required to identify the direction of the different military symbols in the white dotted line box on the map. In second task, after identification, the subjects were required to report the number of military symbols in eight directions: up, down, left, right, upper right, lower right, upper left, and lower left. After the completion of the task, the scale was completed by the subjects to evaluate and give feedback on the six dimensions in the NASA-TLX scale. Figure 25 shows the form of the scale. 


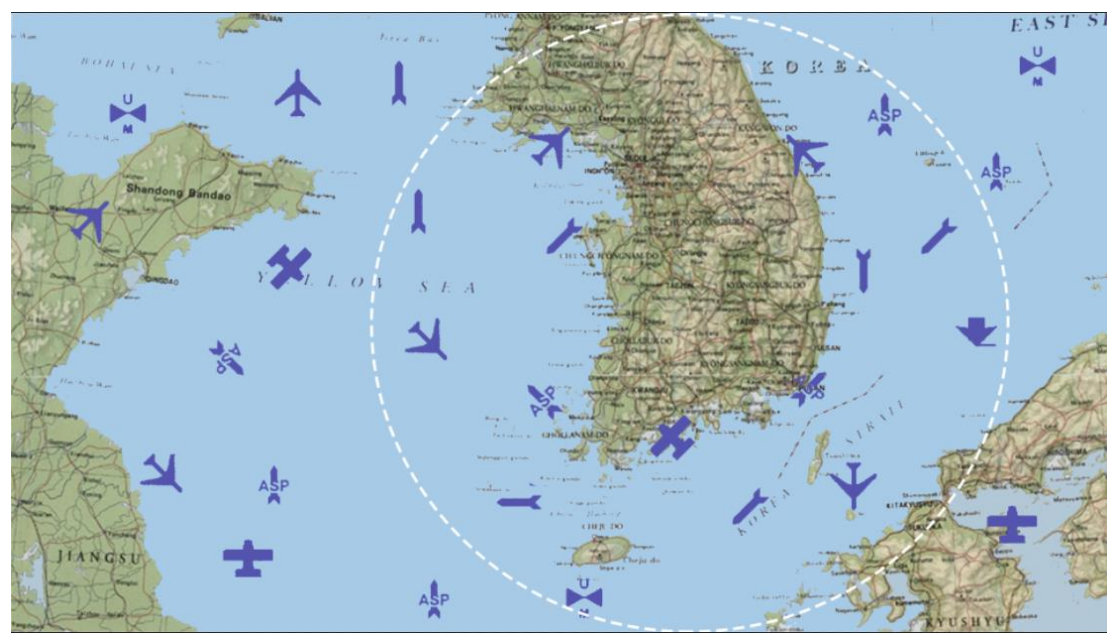

Figure 24. Task interface in the verification experiment.

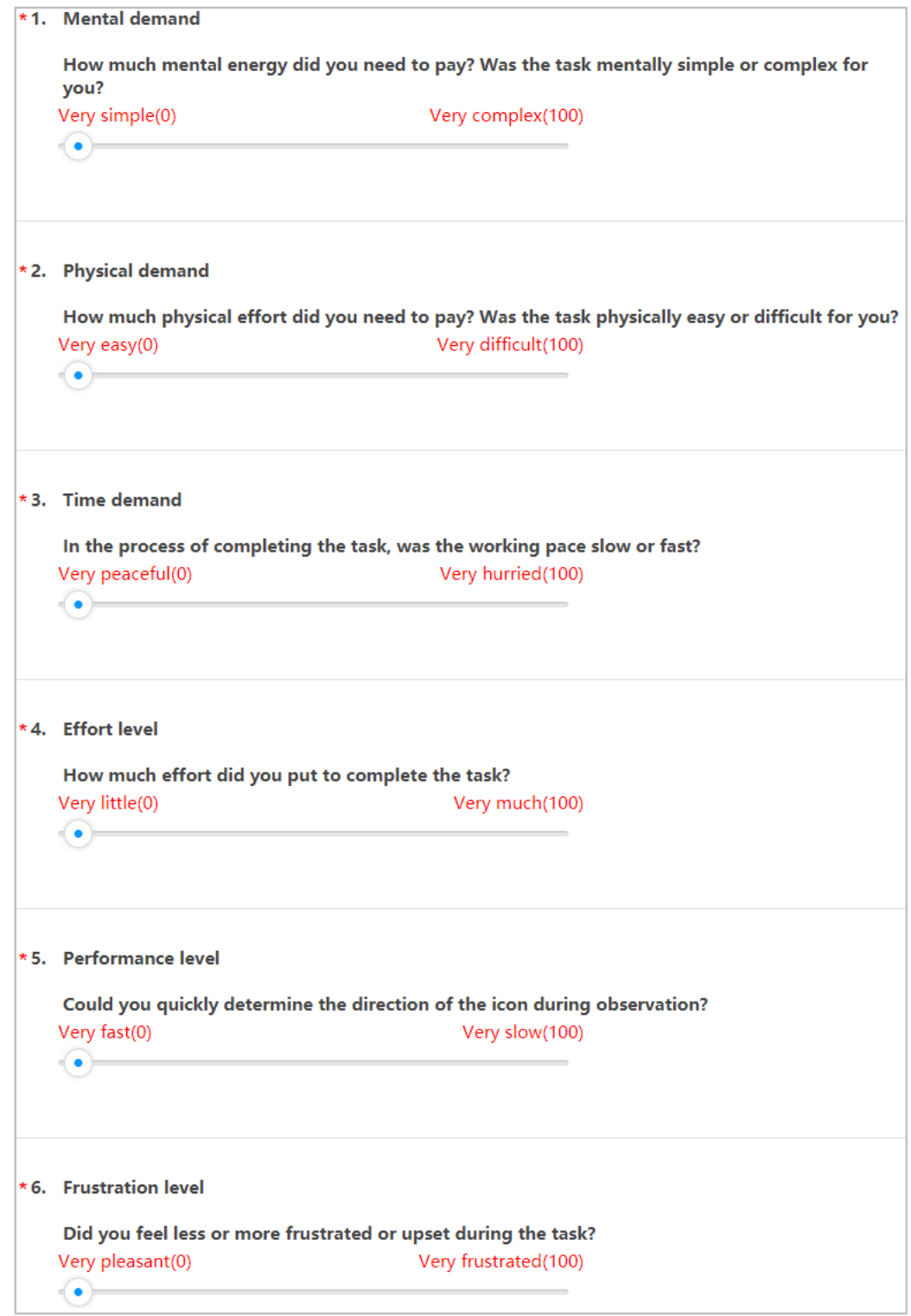

Figure 25. Content of the questionnaire according to NASA-TLX scale [70]. 
Upon completion of the task, all of the subjects filled in the NASA-TLX scale questionnaire. In the verification experiment, a total of 30 scale questionnaires were sent out and all 30 were returned completed; thus, the completion rate of each scale was $100 \%$, all of which were valid questionnaires. Figure 26 shows the results after importing the 30 groups of data into the SPSS software for analysis and for drawing the box plot.

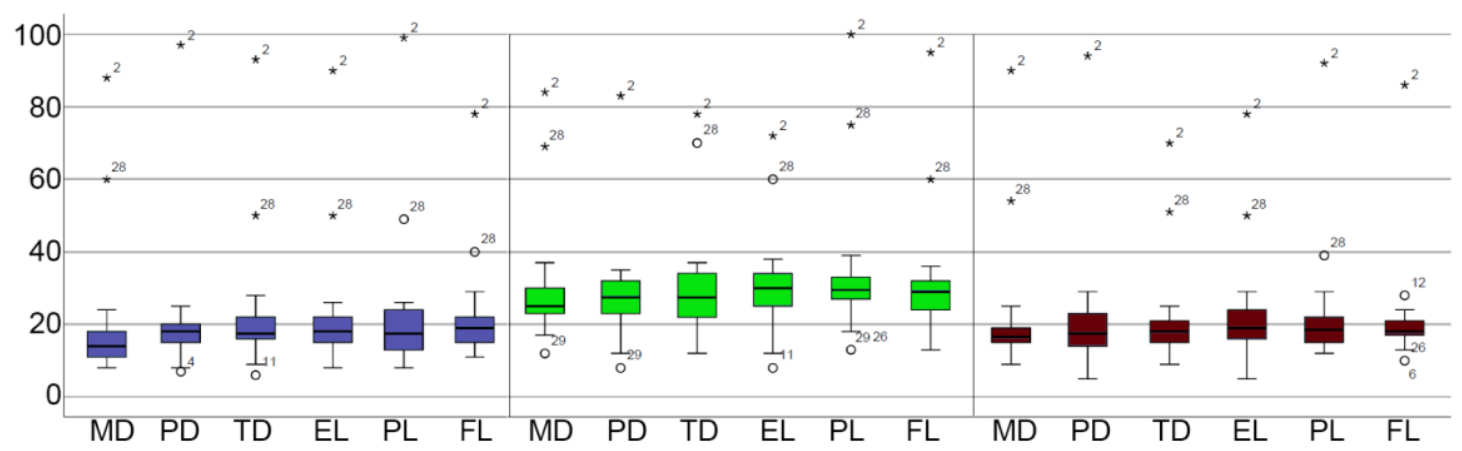

Figure 26. Box plot of the NASA-TLX results. MD, mental demand; PD, physiological demand; TD, time demand; EL, effort level; PL, performance level; FL, frustration level.

In the interface of the map with military symbols of the blue 5 color, the users' score of the six dimensions is around 20, and the abnormal data are marked in the form of scattered points in the figure, as can be seen from Figure 26. The median of each dimension is lower than 20, belonging to the low task difficulty range, indicating that users are satisfied with the blue 5 color for the military symbols. Therefore, it can be confirmed that blue 5 has low subjective task load, and this color has great reference value.

Similarly, in the interface of the map with military symbols of then the green 4 color, the users' score of the six dimensions is around 30, and the abnormal data are marked in the form of scattered points in the figure. The median and quarters of each dimension are between 20 and 40, belonging to the medium-low task difficulty range, indicating that users are relatively satisfied with the green 4 color for the military symbols. Therefore, it can be confirmed that green 4 has medium-low subjective task load, and this color has medium reference value.

Finally, in the interface of the map with military symbols of the red 3 color, the users' score of the six dimensions is around 20, and the abnormal data are marked in the form of scattered points in the figure. The median of each dimension is lower than 20, belonging to the low task difficulty range, which indicated that users are satisfied with the red 3 color for the military symbols. Therefore, it can be confirmed that red 3 has low subjective task load, and this color has great reference value.

\section{Conclusions}

This paper studied the color matching relationship between the background and military symbols of sea situation maps. With the participation of 20 subjects, based on the analysis of the amplitude and latency of the P300 component in the EEG experimental data and the comprehensive evaluation of the fusion behavior data, joined with a valid verification experiment, the following conclusions are drawn:

(1) The P300 components in EEG are induced by different colors of military symbols, among which the P300 amplitude is smaller and the latency is shorter when the color Chroma is lower; thus, the user experience and efficiency of lower Chroma colors are better than those of high Chroma. The P300 component changes that are caused by the three different color Hues are significantly reflected on the P3 and Pz electrodes located in the parietal lobe.

(2) The amplitude of the P300 wave caused by map military symbols with high-Value colors is higher, and latency is longer, indicating a poor performance. Based on EEG data, together with 
behavioral data, the optimal color values of blue, green, and red Hues are given, as follows: blue of $\mathrm{L}=39, \mathrm{a}=20$, and $\mathrm{b}=-49$; green of $\mathrm{L}=80, \mathrm{a}=-72$, and $\mathrm{b}=72$; and, red of $\mathrm{L}=20, \mathrm{a}=41$, and $\mathrm{b}=28$.

(3) The conclusion above was used to design three test interfaces. The verification experiment, evaluated by the NASA-TLX scale, showed that the above-mentioned optimal three colors have less task load, which proves that they have an application value in maps.

\section{Future Work}

There are still some shortcomings in this study: for example: (1) the selection of colors has some limitations. When considering the complexity of the task of the EEG experiment, only several of the typical colors from the MCS were used. Therefore, more colors could be selected for future research. (2) A greater variety of military symbols could be used, thus increasing the task difficulty and further improving the differentiation between the experimental results of different colors. Only directional military symbols were selected; other dimensions were not considered, such as line size and style, which could be extended in the future. (3) Most of the subjects were graduate students, lacking expert user comments on the interface of the situation maps. (4) When using ERP technology to evaluate the colors of the military symbols used in maps, blue, green, and red Hue colors cause different EEG components. In particular, red Hues not only cause the P300 component, but also obvious N200 components appear in the experiment. Thus, it is suggested that the specific components produced by different colors should be further studied by subsequent researchers in relevant studies.

Author Contributions: Conceptualization, Yafeng Niu and Chengqi Xue; methodology, Guorui Ma and Wei Xue; software, Tao Jin; validation, Guorui Ma, Wei Xue and Tao Jin; investigation, Hongrui Zuo; resources, Yue Gao; data curation, Tianyu Zhou; writing —original draft preparation, Guorui Ma; writing—review and editing, Guorui Ma; visualization, Guorui Ma; supervision, Yafeng Niu and Chengqi Xue; project administration, Yafeng Niu and Chengqi Xue; funding acquisition, Yafeng Niu and Chengqi Xue. All authors have read and agreed to the published version of the manuscript.

Funding: This work was supported jointly by National Natural Science Foundation of China (No. 71801037, 71871056, 71901061, 71471037), Fundamental Research Funds for the Central Universities of China (No. 2242019k1G023, 2242019k1G016, 18CX02087A), Aerospace Science Foundation of China (No. 20165169017, 20185569008, 201913069001, 201955069002), Equipments Pre-Research Foundation of China (No.41412040304), Humanities and Social Sciences Research of the Ministry of Education (No. 16YJCZH037).

Acknowledgments: The authors would like to thank all the reviewers for their helpful comments and suggestions.

Conflicts of Interest: The authors declare no conflict of interest.

\section{References}

1. Jiang, J.J.; Wang, Y.Q.; Zhang, L.; Wu, D.Q.; Li, M.; Xie, T.; Li, P.C.; Dai, L.C.; Li, P.Y.; Shi, X.Y.; et al. A cognitive reliability model research for complex digital human-computer interface of industrial system. Saf. Sci. 2018, 108, 196-202. [CrossRef]

2. Ulf Ahlstrom, L.A. Color Usability on Air Traffic Control Displays. Hum. Factors Ergon. Soc. Annu. Meet. Proc. 2005, 49. [CrossRef]

3. Chiang, Y.Y.; Leyk, S.; Nazari, N.H.; Moghaddam, S.; Tan, T.X. Assessing the impact of graphical quality on automatic text recognition in digital maps. Comput. Geosci. 2016, 93, 21-35. [CrossRef]

4. Li, L.; Hasegawa, K.; Nii, I.; Tanaka, S. Fused Transparent Visualization of Point Cloud Data and Background Photographic Image for Tangible Cultural Heritage Assets. ISPRS Int. Geo-Inf. 2019, 8, 343. [CrossRef]

5. Boulhic, L.; Bignon, A.; Silone, F.; Morineau, T.; Rechard, J.; Bouillon, J.-F. Effects of color codes used on marine supervision HMI on mental workload and information retrieval: Experimentations with novices and experts. Int. J. Ind. Ergon. 2018, 67, 180-191. [CrossRef]

6. Yang, C.N. The Study and Application of Flat Design Style Interface Based on Color Psychological Effect. Xi'an Polytechnic University. 2016. Available online: http://kns.cnki.net/kns/detail/detail.aspx?FileName= 1016094262.nh\&DbName=CMFD2016. (accessed on 16 May 2020).

7. Sun, W.T.M.R.J.; Qin, S.Y.; Ai, X.; Xu, J.Y.; Hou, Y.P.; Zhang, G.Y. Application of Color Matching Method Based on Image Derivation In APP Interface Design. Microcomput. Appl. 2017, 33, 22-25. 
8. Tian, J.; Peng, K.; Jia, F.; Xia, Q. The Concept of Symbol-morpheme and its Application in Map Symbols Design. In Proceedings of the 2013 21st International Conference on Geoinformatics, Kai Feng, China, 20-22 June 2013.

9. Scholz, R.W.; Lu, Y.M. Uncertainty in Geographic Data on Bivariate Maps: An Examination of Visualization Preference and Decision Making. ISPRS Int. Geo-Inf. 2014, 3, 1180-1197. [CrossRef]

10. Akcay, O.; Avsar, E.O.; Inalpulat, M.; Genc, L.; Cam, A. Assessment of Segmentation Parameters for Object-Based Land Cover Classification Using Color-Infrared Imagery. ISPRS Int. Geo-Inf. 2018, 7, 424. [CrossRef]

11. Shive, J.; Francis, G. Choosing Colors for Map Display Icons Using Models of Visual Search. Hum. Factors 2013, 55, 373-396. [CrossRef]

12. Skopeliti, A.; Stamou, L. Online Map Services: Contemporary Cartography or a New Cartographic Culture? ISPRS Int. Geo-Inf. 2019, 8, 215. [CrossRef]

13. Li, W.; Chen, Y.; Qian, L.; Liu, X. Personalized Map Symbol Design Mechanism Based on Linguistics. Acta Geod. Cartogr. Sin. 2015, 44, 323-329.

14. Tian, J.; Jia, F.; Xia, Q.; Wu, J. Design Method of the Semantic-driven Hierarchical Map Symbols. J. Geo-Inf. Sci. 2012, 14, 736-743. [CrossRef]

15. Ooms, K.; De Maeyer, P.; Fack, V. Analysing Eye Movement Patterns To Improve Map Design. In Proceedings of the AutoCarto 2010, Cartography and Geographic Information Society (CaGIS), Orlando, FL, USA, 15-18 November 2010; Volume 38.

16. Coeltekin, A.; Brychtova, A.; Griffin, A.L.; Robinson, A.C.; Imhof, M.; Pettit, C. Perceptual complexity of soil-landscape maps: A user evaluation of color organization in legend designs using eye tracking. Int. J. Digit. Earth 2017, 10, 560-581. [CrossRef]

17. Liu, X.; Chen, Y. Frame Design for Point-shaped Map Symbol Based on Eye Movement Experiment. J. Geomat. Sci. Technol. 2016, 33, 644-649.

18. Babiloni, F.; Babiloni, C.; Carducci, F.; Fattorini, L.; Anello, C.; Onorati, P.; Urbano, A. High resolution EEG: A new model-dependent spatial deblurring method using a realistically-shaped MR-constructed subject's head model. Electroencephalogr. Clin. Neurophysiol. 1997, 102, 69-80. [CrossRef]

19. Rahm, B.; Kaiser, J.; Unterrainer, J.M.; Simon, J.; Bledowski, C. fMRI characterization of visual working memory recognition. Neuroimage 2014, 90, 413-422. [CrossRef]

20. Perri, R.L.; Berchicci, M.; Bianco, V.; Quinzi, F.; Spinelli, D.; Di Russo, F. Perceptual load in decision making: The role of anterior insula and visual areas. An ERP study. Neuropsychologia 2019, 129, 65-71. [CrossRef]

21. Kutas, M.; McCarthy, G.; Donchin, E. Augmenting Mental Chronometry-P300 As A Measure of Stimulus Evaluation Time. Science 1977, 197, 792-795. [CrossRef]

22. Niu, Y.F.; Xue, C.Q.; Zhou, X.Z.; Zhou, L.; Xie, Y.; Wang, H.Y.; Tang, W.Z.; Wu, W.Y.; Guo, Q.; Jin, T. Which is more prominent for fighter pilots under different flight task difficulties: Visual alert or verbal alert? Int. J. Ind. Ergon. 2019, 72, 146-157. [CrossRef]

23. Gao, T.T. Data Visualization Cognitive Load Research Based on ERP/EEG Mobile Terminal; Donghua University: Shanghai, China, 2018.

24. Niu, Y.; Xue, C.; Li, X.; Li, J.; Wang, H.; Jin, T. Icon memory research under different time pressures and icon quantities based on event-related potential. J. Southeast Univ. 2014, 30, 45-50.

25. Chen, W.W.W.; Fang, Z. Study of personality characters, psychological health state and auditory P300 on pilots. Clin. Electroencephalol. 1997, 06, 226-228.

26. Zhang, J.L. Analysis on Mental Stress of Pilots with Different Personality in Simulated Flight; Medical school of Chinese PLA: Shanghai, China, 2013.

27. Jin, T.; Xue, C.; Wang, H.; Niu, Y. Research on evaluating methods of situation awareness of digital graphical interfaces. Chin. J. Eng. Des. 2014, 21, 87-91.

28. Yeh, Y.-Y.; Lee, D.-S.; Ko, Y.-H. Color combination and exposure time on legibility and EEG response of icon presented on visual display terminal. Displays 2013, 34, 33-38. [CrossRef]

29. Zhao, Z.G.L.J.L.; Wang, K. The Concept, Structure and Efficiency of Battlefield Situation Assessment. J. CAE 2010, 5, 226-230.

30. Yuan, K.S.Z.R.Q.; Wang, Y.J.; Lu, B.Y. Study on Fundamental Conceptions and Subject System of the Modern Map and Cartography. Geo-Inf. Sci. 2007, 9, 100-108. 
31. Liu, L.Y.Y.F.; Ma, Y.R. The construction of Bohai marine reserve from the perspective of ecological civilization. Dong Yue Trib. 2013, 34, 33-35.

32. DoD(USA). MIL-STD-2525C, Common Warfighting Symbology. In Interface Standard; DOD: Washington, DC, USA, 2008.

33. Ma, S.H.Y.Z. Application of color in ergonomics. Sci. Technol. Inf. 2009, 24, 70.

34. QI Yong, X.Y.-f. Research on the Application of Munsell Color System in LED Image Display. Adv. Disp. 2012, 140, 171-175.

35. Jimenez, R.; Redondo, B.; Molina, R.; Angel Martinez-Domingo, M.; Hernandez-Andres, J.; Vera, J. Short-term effects of text-background color combinations on the dynamics of the accommodative response. Vis. Res. 2020, 166, 33-42. [CrossRef]

36. Prasad, D.K.; Wenhe, L. Metrics and statistics of frequency of occurrence of metamerism in consumer cameras for natural scenes. J. Opt. Soc. Am. A-Opt. Image Sci. Vis. 2015, 32, 1390-1402. [CrossRef]

37. Ikeda, M.; Yaguchi, H.; Sagawa, K. Brightness Luminous-Efficiency Functions for 2-Degree and 10-Degree Fields. J. Opt. Soc. Am. 1982, 72, 1660-1665. [CrossRef] [PubMed]

38. Trezona, P.W. Derivation of the 1964 CIE 10 degrees XYZ colour-matching functions and their applicability in photometry. Color Res. Appl. 2001, 26, 67-75. [CrossRef]

39. Wei, J.H.L.Y.J. The Theory and Technology of Event-Related Potentials; Science Press: Beijing, China, 2010; pp. 52-55.

40. Clifford, A.; Holmes, A.; Davies, I.R.L.; Franklin, A. Color categories affect pre-attentive color perception. Biol. Psychol. 2010, 85, 275-282. [CrossRef] [PubMed]

41. Oxner, M.; Rosentreter, E.T.; Hayward, W.G.; Corballis, P.M. Prediction errors in surface segmentation are reflected in the visual mismatch negativity, independently of task and surface features. J. Vis. 2019, 19. [CrossRef] [PubMed]

42. Wiens Stefan, v.B.E. Szychowska Malina, Eklund Rasmus. Visual Perceptual Load Does Not Affect the Frequency Mismatch Negativity. Front. Psychol. 2019, 10, 1970. [CrossRef]

43. Male, A.G.; O'Shea, R.P.; Schroger, E.; Muller, D.; Roeber, U.; Widmann, A. The quest for the genuine visual mismatch negativity (vMMN): Event-related potential indications of deviance detection for low-level visual features. Psychophysiology 2020. [CrossRef]

44. Delogu, F.; Brouwer, H.; Crocker, M.W. Event-related potentials index lexical retrieval (N400) and integration (P600) during language comprehension. Brain Cogn. 2019, 135. [CrossRef]

45. Liu, B.; Wu, G.; Meng, X.; Dang, J. Correlation Between Prime Duration and Semantic Priming Effect: Evidence From N400 Effect. Neuroscience 2013, 238, 319-326. [CrossRef]

46. Rama, P.; Sirri, L.; Serres, J. Development of lexical-semantic language system: N400 priming effect for spoken words in 18-and 24-month old children. Brain Lang. 2013, 125, 1-10. [CrossRef]

47. Proverbio, A.M.; Riva, F. RP and N400 ERP components reflect semantic violations in visual processing of human actions. Neurosci. Lett. 2009, 459, 142-146. [CrossRef]

48. Morrison, C.; Taler, V. ERP measures of the effects of age and bilingualism on working memory performance. Neuropsychologia 2020, 143, 107468. [CrossRef] [PubMed]

49. Han, T.; Xiu, L.C.; Yu, G.M. The impact of media situation on people's memory effect-An ERP study. Comput. Hum. Behav. 2020, 104. [CrossRef]

50. Berti, S.; Haycock, B.; Adler, J.; Keshavarz, B. Early cortical processing of vection-inducing visual stimulation as measured by event-related brain potentials (ERP). Displays 2019, 58,56-65. [CrossRef]

51. Liu, Q.A.; Li, H.; Jennifer, L.C.; Teeter, C.; Tao, W.D.; Zhang, Q.L.; Sun, H.J. Language suppression effects on the categorical perception of colour as evidenced through ERPs. Biol. Psychol. 2010, 85, 45-52. [CrossRef]

52. Martin, F.M.D.; Hauk, O.; Pulvermuller, F. Category specificity in the processing of color-related and form-related words: An ERP study. Neuroimage 2006, 29, 29-37. [CrossRef] [PubMed]

53. Picton, T.W.; Bentin, S.; Berg, P.; Donchin, E.; Hillyard, S.A.; Johnson, R.; Miller, G.A.; Ritter, W.; Ruchkin, D.S.; Rugg, M.D.; et al. Guidelines for using human event-related potentials to study cognition: Recording standards and publication criteria. Psychophysiology 2000, 37, 127-152. [CrossRef]

54. Ragain, J.C.; Johnson, W.M. Color acceptance of direct dental restorative materials by human observers. Color. Res. Appl. 2000, 25, 278-285. [CrossRef]

55. Craig, J.M.P. Restorative Dental Materials, 11th ed.; Mosby: St. Louis, MO, USA, 2002; pp. $38-42$. 
56. Wee, A.G.; Lindsey, D.T.; Kuo, S.L.; Johnston, W.M. Color accuracy of commercial digital cameras for use in dentistry. Dent. Mater. 2006, 22, 553-559. [CrossRef]

57. McLaren, K. Development of Cie 1976 (Lab) Uniform Color Space And Color-Difference Formula. J. Soc. Dye. Colour. 1976, 92, 338-341. [CrossRef]

58. Liu, L.L.; Wang, X.H.; Li, J. The establishment of uniform color space based on LCD monitor. Optik 2017, 139, 338-346. [CrossRef]

59. Martinez-Domingo, M.A.; Melgosa, M.; Okajima, K.; Medina, V.J.; Collado-Montero, F.J. Spectral Image Processing for Museum Lighting Using CIE LED Illuminants. Sensors 2019, 19, 5400. [CrossRef] [PubMed]

60. Chen, M.; Fadel, G.; Xue, C.Q.; Wang, H.Y.; Mata, I.; Chen, Y.F. Evaluating the cognitive process of color affordance and attractiveness based on the ERP. Int. J. Interact. Des. Manuf. 2017, 11, 471-479. [CrossRef]

61. Hasan, R.A.; Reza, F.; Begum, T. Gender Influences on Colour processing: An event related potential (ERP) study. Bangladesh J. Med Sci. 2018, 17, 612-618. [CrossRef]

62. Kramer, A.F.; Wickens, C.D.; Donchin, E. An Analysis of The Processing Requirements of A Complex Perceptual-Motor Task. Hum. Factors 1983, 25, 597-621. [CrossRef] [PubMed]

63. Polich, J. Task-Difficulty, Probability, and Inter-Stimulus Interval as Determinants Of P300 from Auditory-Stimuli. Electroencephalogr. Clin. Neurophysiol. 1987, 68, 311-320. [CrossRef]

64. Polich, J. Updating p300: An integrative theory of P3a and P3b. Clin. Neurophysiol. 2007, 118, $2128-2148$. [CrossRef]

65. Shou, G.F.; Ding, L.; IEEE. Neural Markers for Immediate Performance Accuracy in a Stroop Color-word Matching Task: An Event-related Potentials Analysis. In Proceedings of the 2014 36th Annual International Conference of the IEEE Engineering in Medicine and Biology Society, Chicago, IL, USA, 26-30 August 2014; pp. 6222-6225.

66. Andrew, A.; Fingelkurts, A.A.F. Operational Architectonics of the Human Brain Biopotential Field: Towards Solving the Mind-Brain Problem. Brain Mind 2001, 2, 261-296.

67. Wicke, J.D.; Lindsley, D.B.; Donchin, E. Visual Evoked Potentials as Function of Flash Luminance + Duration. Science 1964, 146, 83. [CrossRef]

68. Ecker, U.K.H.; Zimmer, H.D.; Groh-Bordin, C. The influence of object and background color manipulations on the electrophysiological indices of recognition memory. Brain Res. 2007, 1185, 221-230. [CrossRef]

69. Gan, T.; Fang, W.; Ge, L.Z. Colours' Impact on Morality: Evidence from Event-related Potentials. Sci. Rep. 2016, 6. [CrossRef]

70. Fuller, T.E.; Garabedian, P.M.; Lemonias, D.P.; Joyce, E.; Schnipper, J.L.; Harry, E.M.; Bates, D.W.; Dalal, A.K.; Benneyan, J.C. Assessing the cognitive and work load of an inpatient safety dashboard in the context of opioid management. Appl. Ergon. 2020, 85. [CrossRef] [PubMed] 